Full Length Article

\title{
Transesterification of high-acidity spent coffee ground oil and subsequent combustion and emissions characteristics in a compression-ignition engine
}

\author{
Ioannis Efthymiopoulos ${ }^{\mathrm{a}, *}$, Paul Hellier ${ }^{\mathrm{a}}$, Nicos Ladommatos ${ }^{\mathrm{a}}$, Ben Mills-Lamptey ${ }^{\mathrm{b}}$ \\ ${ }^{a}$ Department of Mechanical Engineering, University College London, Torrington Place, London WC1E 7JE, United Kingdom \\ ${ }^{\mathrm{b}}$ bio-bean Ltd., Unit 4002, Alconbury Weald Enterprise Park, Alconbury, Huntingdon PE28 4WX, United Kingdom
}

\section{A R T I C L E I N F O}

\section{Keywords:}

Spent coffee biodiesel

Two-step transesterification

Methyl esters

Fatty acid profile

Compression-ignition combustion

Biodiesel emissions

\begin{abstract}
A B S T R A C T
Lipids extracted from spent coffee grounds (SCG) are a potentially promising feedstock for biodiesel production if the relatively high free fatty acid (FFA) portion of the oil can be successfully converted into methyl esters, and the resulting biodiesel found to have acceptable combustion and emissions performance. This study presents experimental results obtained from transesterification of SCG-extracted oil with a FFA content of $\sim 30 \% \mathrm{w} / \mathrm{w}$ through a two-step process, followed by fuel characterization and combustion experiments with SCG-derived biodiesel, pure and blended with fossil diesel, and untreated SCG oil in a single cylinder research compressionignition engine. The acid-catalyzed pretreatment reduced the FFA content of the oil below $1.5 \%$ w/w, with minor losses, and showed the methanol-to-FFA molar ratio to be more significant relative to the quantity of sulphuric acid used as a catalyst within the range of investigated conditions, while the subsequent base-catalyzed step converted $\sim 87 \%$ of the pretreated oil into biodiesel with a higher heating value (HHV) of $39.7 \mathrm{MJ} / \mathrm{kg}$. The combustion and emission characteristics of pure and blended SCG biodiesel revealed similarities with those of commercial rapeseed and soya biodiesel samples tested. While ignition delay decreased with increasing SCG biodiesel content, the comparatively higher CO, total hydrocarbon (THC) and particulate emissions of the SCG biodiesel were attributed to higher fuel kinematic viscosity (KV). Combustion of the untreated SCG oil produced low in-cylinder peak pressure and peak heat release relative to other samples tested despite a longer ignition delay, suggesting that the oil physical properties were more important in determining combustion performance.
\end{abstract}

\section{Literature review}

Nowadays, fossil fuels continue to account for the majority of global energy consumption, constituting $86 \%$ of the total energy consumed in 2016 , however, their continuous use in combustion related activities is responsible for the increasing concentration of greenhouse gases in the atmosphere $[3,25]$. Therefore, there is a need for sustainable alternatives to fossil fuels in order to reduce the emissions of greenhouse gases and avoid harmful climate change, while simultaneously addressing the continuous increase in energy demand [3,13,49]. Lipids found in SCG have been suggested to be a promising feedstock for the production of biodiesel, which has been widely considered and utilized as a renewable substitute for fossil diesel fuel $[1,38]$. The glycerides and FFAs present in the SCG oil can be transesterified with short chain monohydric alcohols, such as ethanol or methanol, in the presence of a catalyst at elevated temperature, to yield fatty acid alkyl esters (FAAE) $[1,39]$.

However, the conversion level of vegetable oils to biodiesel is strongly dependent on the quality of the feedstock, with SCG oil showing a significant degree of variation in terms of FFA content with typical values ranging between $\sim 3 \% \mathrm{w} / \mathrm{w}$ and $\sim 20 \% \mathrm{w} / \mathrm{w}$ $[1,6,12,17,15]$, although FFA contents as high as $59 \%$ have been previously reported [6]. A FFA content above $1-1.5 \% \mathrm{w} / \mathrm{w}$ of the oil inhibits alkaline transesterification by forming stable soap emulsions that impede separation of FAAEs from glycerol $[1,6,12]$. Furthermore, soaps bind with the alkali catalyst and consequently higher quantities of catalyst are required [40], though FFAs can react with an alcohol and convert into alkyl esters in acid-catalyzed processes [40]. In addition, an increased $\mathrm{KV}$ of the oil, due to the presence of FFAs, increases the power consumption for mixing the reactants during transesterification

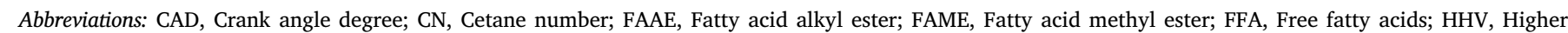

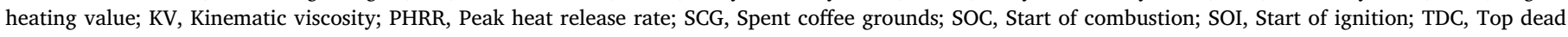
center; THC, Total hydrocarbon

* Corresponding author.

E-mail address: i.efthymiopoulos@ucl.ac.uk (I. Efthymiopoulos). 
Table 1

Properties of SCG biodiesel.

\begin{tabular}{|c|c|c|c|c|c|}
\hline References & Density at $15^{\circ} \mathrm{C}\left(\mathrm{kg} / \mathrm{m}^{3}\right)$ & $\mathrm{KV}$ at $40^{\circ} \mathrm{C}\left(\mathrm{mm}^{2} / \mathrm{s}\right)$ & HHV (MJ/kg) & Acid value $\left(\mathrm{mg}_{\mathrm{Kон}} / \mathrm{g}\right)$ & Oxidation stability at $110^{\circ} \mathrm{C}(\mathrm{h})$ \\
\hline Deligiannis et al. [12] & 894.3 & 5.61 & 39.49 & 0.36 & 7.9 \\
\hline Haile [19] & 880 & 5.4 & 39.6 & 0.7 & - \\
\hline Berhe et al. [2] & 891.5 & 5.26 & 38.4 & 0.78 & - \\
\hline Caetano et al. [6] & 911 & 12.88 & - & 2.14 & - \\
\hline Kondamudi et al. [38] & - & 5.84 & - & 0.35 & 3.05 \\
\hline Tuntiwiwattanapun et al. [58] & - & $3.81-4.33$ & - & $1.40-5.10$ & $4.9-8.8$ \\
\hline Jenkins et al. [27] & $841-927$ & $3.5-5.5$ & - & - & - \\
\hline Vardon et al. [59] - B100 & 892 & 5.19 & 39.6 & 0.11 & 0.2 \\
\hline Vardon et al. [59] - B20 & 856.4 & 2.75 & 43.9 & 0.16 & 5.2 \\
\hline Vardon et al. [59] - B5 & 850.1 & 2.40 & 44.8 & 0.17 & 13.2 \\
\hline EN 14214 & $860-900$ & $3.5-5$ & - & $<0.5$ & $>8$ \\
\hline
\end{tabular}

and leads to lower biodiesel yields [1,42].

Three main methods have been applied in previous studies for the transesterification of SCG lipids including a base-catalyzed [1,5,12,38], an acid-catalyzed $[27,39,50]$, and a two-step process consisting of an initial acid-catalyzed esterification of FFAs followed by base-catalyzed transesterification, which has been described as the most efficient procedure for conversion of SCG oil samples with high FFA content $(3.65-59.5 \% \mathrm{w} / \mathrm{w})$ that inhibits a direct base-catalyzed process $[1,2,5,6,19,59]$. Compared to saponification of FFAs prior to further processing, acid-catalyzed pretreatment converts the FFAs into fatty acid methyl esters (FAMEs) [40], while the two-step process has been found to result in high conversion yields in a fraction of the time that would be required in a single acid-catalyzed process [8]. Other techniques that include the use of lipases as catalysts $[18,56]$, or the direct transesterification of wet or dried SCG prior to oil extraction $[7,41,45,46,58]$ have also been investigated.

Previous studies have utilized a range of conditions during two-step transesterification of SCG oil. Haile [19] mixed the oil (4.9\% w/w FFA content) three consecutive times with methanol at a molar ratio of alcohol to FFA of $20: 1$ in the presence of $\mathrm{HCl}(10 \% \mathrm{w} / \mathrm{w}$ of total fatty acid content) for $90 \mathrm{~min}$ at a temperature of $54^{\circ} \mathrm{C}$ to achieve a FFA level of $0.5 \% \mathrm{w} / \mathrm{w}$, before proceeding to the alkaline reaction at the same duration and temperature conditions, with a methanol to oil molar ratio of 9:1 and $1 \% \mathrm{w} / \mathrm{w}$ of $\mathrm{KOH}$ achieving a FAME yield of $82 \% \mathrm{w} / \mathrm{w}$. Berhe et al. [2] achieved a FAME yield of 73.4\% w/w from SCG oil $(7.36 \% \mathrm{w} /$ $\mathrm{w}$ initial FFA content) by performing both stages of the process at a higher temperature $\left(60^{\circ} \mathrm{C}\right)$ and longer duration $(120 \mathrm{~min})$ but at the same methanol and catalyst ratios as Haile [19], although $\mathrm{HCl}$ and $\mathrm{KOH}$ were substituted with $\mathrm{H}_{2} \mathrm{SO}_{4}$ and $\mathrm{NaOH}$, and the FFA content of the oil after pretreatment was $0.9 \% \mathrm{w} / \mathrm{w}$.

Vardon et al. [59] treated SCG lipids $(5.66 \% \mathrm{w} / \mathrm{w}$ initial FFA content) with $35 \% \mathrm{v} / \mathrm{v}$ methanol and $1 \% \mathrm{v} / \mathrm{v}$ sulfuric acid at reflux for $4 \mathrm{~h}$, and subsequently mixed the oil with methanol (6:1 methanol molar ratio) and $0.5 \% \mathrm{w} / \mathrm{w}$ sodium methoxide $\left(\mathrm{CH}_{3} \mathrm{ONa}\right)$ relative to lipid weight in a reflux condenser for $1 \mathrm{~h}$ to obtain a FAME yield of $96 \% \mathrm{w} /$ w. Caetano et al. [6] extracted SCG lipids with $59.5 \%$ w/w FFA content and performed three successive esterifications with $40 \% \mathrm{w} / \mathrm{w}$ methanol and $1 \% \mathrm{w} / \mathrm{v} \mathrm{H}_{2} \mathrm{SO}_{4}$ for $2 \mathrm{~h}$ at $60^{\circ} \mathrm{C}$, followed by an alkali-catalyzed reaction with $40 \% \mathrm{w} / \mathrm{w}$ methanol and previously dissolved $1 \% \mathrm{w} / \mathrm{w}$ $\mathrm{NaOH}$ at the same conditions of duration and temperature to obtain a relatively low conversion yield of $60.5 \% \mathrm{w} / \mathrm{w}$, suggesting that, despite the three esterification steps the FFA content was still sufficiently high to lead to soap formation and hinder the reaction.

Al-Hamamre et al. [1] initially converted FFAs to esters by mixing oil (3.65\% w/w FFA content) with $20 \% \mathrm{v} / \mathrm{v}$ methanol and $0.1 \% \mathrm{v} / \mathrm{v}$ sulfuric acid for $4 \mathrm{~h}$ and transesterified the pre-treated oil with methanol $\left(6: 1 \mathrm{M}\right.$ ratio to oil) and $1.5 \% \mathrm{KOH}$ for $6 \mathrm{~h}$ at $60^{\circ} \mathrm{C}$ to achieve a conversion rate of $99 \%$. A comparison between single base-catalyzed transesterification and two-step transesterification performed with lipids of the same FFA content $(3.65 \% \mathrm{w} / \mathrm{w})$ showed that the two-step process resulted in a higher FAME yield, while the amount of catalyst required in the second step was lower relative to single alkaline transesterification due to reduction of the FFA content [1].

Generally, previous studies have shown that an increase in the amount of catalyst used in the acid-catalyzed pretreatment step decreases the FFA content of the oil [8], with a 5\% w/w of sulfuric acid relative to FFA weight working well within the FFA range of 15-35\% $\mathrm{w} / \mathrm{w}$ [10]. Moreover, a molar ratio of methanol to FFA of 19.8:1 to 20:1 has been found to be optimal for acid-catalyzed pretreatment of oil samples with FFA content ranging between 15 and $25 \% \mathrm{w} / \mathrm{w}[5,10,19]$. An esterification duration of $4 \mathrm{~h}$ was found to be sufficient in previous studies that investigated the two-step transesterification of SCG oil, without the need for additional consecutive acid-catalyzed esterification steps for FFA reduction [1,59]. Regarding the base-catalyzed step, a molar ratio of alcohol to triglycerides of $6: 1$ has been found sufficient for a successful conversion of oil into biodiesel, while a catalyst concentration of approximately $1.5 \% \mathrm{w} / \mathrm{w}$ has been reported as optimal in terms of reaction yield $[5,14,40]$.

Several studies have investigated the properties of SCG biodiesel and its suitability as a potential alternative fuel to fossil diesel $[2,6,12,19,27,41,58,59]$. Generally, the FA profile of SCG biodiesel is identical to the fatty acid profile of its source oil [50], and primarily comprises of palmitic and linoleic acid, with lower concentrations of oleic, stearic and eicosanoic acid and traces of other fatty acids. In addition, the fatty acid composition of SCG biodiesel is similar to that of biodiesel produced from soybean and corn [50]. Table 1 shows SCG biodiesel properties measured in previous studies, either as pure FAMEs or blended with diesel at volume ratios of $5 \%$ and $20 \%$ biodiesel. Table 1 also shows the generally applicable diesel quality requirements for use in diesel engines according to European standard EN 14214 [4].

It can be seen in Table 1 that the acid value of SCG biodiesel samples ranges between 0.36 and $5.10 \mathrm{mg}_{\mathrm{KOH}} / \mathrm{g}$, with a value above the standard limit of $0.5 \mathrm{mg}_{\mathrm{KOH}} / \mathrm{g}$ being an indication of incomplete reaction due to high oil FFA content that possibly resulted in soap formation and hindered the transesterification process, as was the case in the study of Caetano et al. [6], and/or an inefficient neutralization procedure $[5,58]$. Biodiesel with an acid value above $0.5 \mathrm{mg}_{\mathrm{KOH}} / \mathrm{g}$ can potentially cause corrosion in diesel engines and fuel sediment leading to filter plugging [58], while a high FAME acid value is also related to high KV [1]. The acid value of SCG biodiesel was reduced by Caetano et al. [5] by ensuring low oil FFA content prior to transesterification, and by reducing the amount of acidic catalyst used for neutralization of the base catalyst in the study of Tuntiwiwattanapun et al. [58].

The KV of pure SCG biodiesel, which affects fuel flow through the fuel supply system and the atomization upon injection [27], was found to range between 3.81 and $12.88 \mathrm{~mm}^{2} / \mathrm{s}$ in previous studies (Table 1), with viscosities above the specification limit of $5 \mathrm{~mm}^{2} / \mathrm{s}$ possibly attributable to incomplete reaction and inefficient purification steps that left glycerol in the ester phase [12], and increasing degree of saturation. Jenkins et al. [27] reported a variation of biodiesel KV between 3.5 and $5.5 \mathrm{~mm}^{2} / \mathrm{s}$ depending on regional origin, bean type and brewing method. In particular, differences in the brewing process impact on the 
KV by removing different compounds prior to oil extraction and esterification [27]. It has been suggested that the KV of SCG biodiesel can be decreased by refining of lipids prior to transesterification, through decreasing the acid value of the fuel and/or by mixing it with conventional diesel $[5,59]$.

Most of the previous studies obtained biodiesel with a density that was within the specification limits (Table 1), a significant result as fuel density is important for diesel fuel injection systems which operate on a volume metering system [12,27], while the relatively high biodiesel density measured by Caetano et al. [6] may be a consequence of incomplete transesterification reaction. Furthermore, the variation in densities of FAMEs obtained from SCG and fresh coffee lipids of different origins and bean types, but similar fatty acid profile, reported by Jenkins et al. [27], suggests that fuel properties such as density and KV also depend on other lipid-soluble compounds present in the SCG biodiesel. However, no input of the brewing process on the resultant FAME density was found by Jenkins et al. [27].

The HHV of SCG biodiesel determined in previous studies (Table 1), was found to be comparable to biodiesel derived from soybean oil $(39.9 \mathrm{MJ} / \mathrm{kg}$ ) and other plant lipid-derived biodiesels [59]. The small difference in the HHV of SCG biodiesel samples reported in previous studies can be likely attributed to the different fatty acid profile of the samples, as the quantity of energy depends on the chain length and degree of unsaturation, with increased presence of unsaturated fatty acids lowering the energy content due to lower energy release upon breakdown of one double bond relative to breakdown of two single bonds [51].

Oxidation stability indicates the resistance of a fuel to oxidation during extended storage [31,58], with biodiesel being significantly more prone to oxidation relative to fossil diesel [12]. Biodiesel produced from coffee oil generally has better oxidative stability relative to biodiesel derived from other sources because of the presence of endogenous antioxidants $[1,12]$, however, such natural antioxidants can be lost during transesterification resulting in a relatively poor oxidative stability of biodiesel [59]. Oxidation rates of biodiesel mainly depend on its fatty acid composition, with monounsaturated fatty acids, such as oleic acid that can be found in relative high proportions in SCG FAMEs, having higher oxidative stability than less saturated molecules without any adverse effect on fuel cold properties [48].

This paper presents both the transesterification of oil extracted at industrial scale from SCGs of the instant coffee industry [16], and the subsequent testing of the obtained biodiesel in a modern diesel engine. The effect of various transesterification parameters on the yield and quality of biodiesel derived from SCG oil containing high FFA content are investigated through a two-step method. SCG biodiesel has been characterized previously in terms of physical and chemical properties, however, no detailed analysis of engine combustion and emission characteristics of these fuels has been reported. The combustion and emission characteristics of SCG oil and biodiesel are determined using a research compression-ignition engine in order to evaluate their performance as diesel fuels and compare the SCG-derived biodiesel with other commercial biodiesel samples.

\section{Methodology}

\subsection{Determination of FFA content through titration}

The acid value and FFA content of the oil and biodiesel samples were determined through the method of titration with phenolphthalein as the indicator [28]. In order to improve the accuracy of the method, which depends on identifying the exact point of color change, and therefore the validity of the obtained results, a $\mathrm{pH}$ meter (Hannah, HI991001) with accuracy of \pm 0.02 was used to detect the equivalence point.

\subsection{Determination of density and kinematic viscosity}

The density of the oil was calculated by adding quantities of $1 \mathrm{ml}$ into a $10 \mathrm{ml}$ volumetric cylinder, measuring the weight on a precision balance and then drawing a graph of mass against volume. Thereafter, a straight best fit line was drawn and the SCG oil density was found from its gradient.

Viscosity measurements were conducted on the steady state mode using a rotational hybrid rheometer (DHR-3, TA Instruments) equipped with a $60 \mathrm{~mm}$ cone geometry ( $1 \mathrm{deg})$ at a gap of $27 \mu \mathrm{m}$. A 6 min equilibration time was applied before each measurement to ensure that the sample had reached the desired temperature $\left(40^{\circ} \mathrm{C}\right)$. The average dynamic viscosity was used for the determination of the KV as per Eq. (1):

$\mathrm{KV}\left(\frac{\mathrm{mm}^{2}}{\mathrm{~s}}\right)=\frac{\text { Dynamic viscosity }(\mathrm{mPa} s)}{\operatorname{Density}\left(\frac{\mathrm{g}}{\mathrm{cm}^{3}}\right)}$

\subsection{Transesterification}

\subsubsection{Acid-catalyzed pretreatment}

SCG oil with FFA content of $29.91 \pm 0.51 \% \mathrm{w} / \mathrm{w}$, which had been previously homogenized by preheating at $55^{\circ} \mathrm{C}$ in a water bath for $30 \mathrm{~min}$, and methanol were mixed in the presence of sulfuric acid at temperatures of $50{ }^{\circ} \mathrm{C}$ and $60^{\circ} \mathrm{C}$, while the stirring speed was kept constant at $600 \mathrm{rpm}$ so as to ensure efficient mixing. The mixture was stirred for $4 \mathrm{~h}$ after the start of the reaction, a duration that was found to be sufficient in previous studies $[1,59]$, and the $\% \mathrm{w} / \mathrm{w}$ FFA content of the mixture was measured at 2,3 and $4 \mathrm{~h}$ through titration.

Pretreated oil samples were left to settle for $24 \mathrm{~h}$ in a separating funnel and the bottom layer was separated from the top layer of unreacted methanol and water with a separation funnel. The resulting sample was then subjected to rotary evaporation to remove any residual methanol and water. Any oil loss relative to the weight of the initial samples was measured according to Eq. (2):

$\% w / w O i l l o s s=\frac{W_{\text {initial }}-W_{\text {pretreated }}}{W_{\text {initial }}} \times 100$

where $\mathrm{W}_{\text {initial }}$ and $\mathrm{W}_{\text {pretreated }}$ correspond to the initial and pre-treated oil respectively.

\subsubsection{Base-catalyzed transesterification}

In this step of the process, pre-treated oil with FFA content below $1.5 \% \mathrm{w} / \mathrm{w}$ was mixed with methanol in the presence of potassium hydroxide. Potassium hydroxide was selected based on the results reported in previous studies that examined the base-catalyzed transesterification of SCG oil, with Al-Hamamre et al. [1] and Kondamudi et al. [38] achieving FAME conversion yields of $99 \% \mathrm{w} / \mathrm{w}$ and $100 \% \mathrm{w} / \mathrm{w}$ respectively with a $\mathrm{KOH}$ catalyst. All the alkali-catalyzed experiments were conducted at a temperature of $60^{\circ} \mathrm{C}$ for $4 \mathrm{~h}$ at varying methanolto-pretreated oil molar ratios and catalyst-to-pretreated oil weight percentages, while the mixture was constantly stirred at $600 \mathrm{rpm}$.

The reaction product was allowed to settle in a separation funnel and after $24 \mathrm{~h}$ the upper biodiesel and unreacted methanol phase was separated from the lower glycerol phase. Unreacted methanol was removed from the FAMEs by rotary evaporation and the resulting ester phase was successively washed with warm $\left(55^{\circ} \mathrm{C}\right)$ distilled water until neutral $\mathrm{pH}$. The $\mathrm{pH}$ was measured constantly by a Hannah, HI991001 $\mathrm{pH}$ meter. The washing process also served as a way to remove residual catalyst, glycerol, methanol and soap from the coffee biodiesel. Thereafter, the FAMEs were subjected to thermal heating at $100{ }^{\circ} \mathrm{C}$ for $5 \mathrm{~h}$ and subsequently a further step of drying with sodium sulfate to remove residual water was carried out. Finally, a filtration process with cellulose membranes (Whatman, 4-7 $\mu \mathrm{m}$ ) was performed to remove solid traces. The $\% \mathrm{w} / \mathrm{w}$ FAME reaction yield relative to pre-treated SCG oil was calculated according to Eq. (3). 
$\%$ Reaction yield $=\frac{w_{\text {FAME }}}{w_{\text {pretreated oil }}} \times 100$

where $\mathrm{W}_{\text {FAME }}$ and $\mathrm{W}_{\text {pretreated oil }}$ represent the mass of biodiesel and pretreated SCG oil respectively.

\subsection{Determination of fatty acid profile}

The FA profile of selected oil samples was determined by gas chromatography coupled with a flame ionization detector, following transesterification of the oil. The Gas Chromatograph was equipped with a Supelco SP-2380 capillary column $(30 \mathrm{~m} \times 0.25 \mathrm{~mm}$ internal diameter, max temperature $275^{\circ} \mathrm{C}$ ) coated with $90 \%$ biscyanopropyl/ $10 \%$ cyanopropylphenyl siloxane stationary phase $(0.2 \mu \mathrm{m}$ film thickness), and a helium mobile phase (flow rate: $20 \mathrm{ml} / \mathrm{min}$ ) which carried the sample molecules through the heated column. An injection port, maintained at $250{ }^{\circ} \mathrm{C}$, and a flame ionization detector $\left(260^{\circ} \mathrm{C}\right)$ were located at the inlet and outlet of the column respectively. The injection volume for each solution was $1 \mu \mathrm{l}$ and the split ratio with the carrier gas $50: 1$. The oven was programmed initially to maintain a temperature of $50{ }^{\circ} \mathrm{C}$ for $2 \mathrm{~min}$ and then increase the temperature up to $250^{\circ} \mathrm{C}$ at a ramp rate of $5{ }^{\circ} \mathrm{C}$ per minute.

\subsection{Determination of higher heating value}

The HHV of SCG oil and biodiesel samples was determined by using an IKA ${ }^{\circledR} \mathrm{C} 1$ Bomb calorimeter system. The bomb calorimeter was connected to a compressed $\mathrm{O}_{2}$ cylinder ( $99.5 \%$ purity) which provided oxygen supply at a pressure of 30 bar through a suitable regulator, and a cooler that provided water at a temperature of $19^{\circ} \mathrm{C}$ [26].

\subsection{Combustion experiments}

\subsubsection{Engine}

Combustion experiments were conducted in a single cylinder, direct injection compression ignition research engine. An ultralow volume fuel system, originally conceived by Schönborn et al. [52] and later redesigned by Hellier et al. [23], which allowed comprehensive engine testing with fuel samples as small as $100 \mathrm{ml}$ was used. This system uses the engine common rail system as a hydraulic fluid supply to pressurize the sample fuel to the desired injection pressure via two free pistons that separate it from the standard common rail diesel fuel [22,34]. A bypass operated by high pressure needle valves allowed fossil reference diesel from the engine pump circuit to flow at pressure and flush the test fuel circuit and combustion chamber between every test run [22]. Fig. 1 shows a schematic of the system.

The in-cylinder gas pressure was continuously measured and logged with a PC data acquisition system (National Instruments) at every 0.2 crank angle degrees (CAD) using a piezoelectric pressure transducer (Kistler 6056AU38) and charge amplifier (Kistler 5011). The in-cylinder gas pressure was pegged each combustion cycle at the bottom dead centre (induction stroke) by a piezoresistive pressure transducer (Druck PTX 7517-3257) located in the engine intake manifold, $160 \mathrm{~mm}$ upstream of the intake valves. The data acquisition system recording the cylinder gas pressure was triggered by a shaft encoder every $0.2 \mathrm{CAD}$, which was the shaft encoder resolution. The shaft encoder also produced a top dead center (TDC) signal, which was recorded by the data acquisition system. For each experiment, 100 consecutive engine cycles were recorded and an average of these was used in the subsequent heat release rate analysis, which was derived from the measured in-cylinder pressure during post-processing (MATLAB).

For each combustion experiment the engine exhaust gas was sampled unfiltered $180 \mathrm{~mm}$ downstream of the exhaust valves and the sample was fed through heated lines $\left(80^{\circ} \mathrm{C}\right)$ to two analyzers. A Horiba MEXA 9100 HEGR was used to determine the dry concentrations of nitrogen oxides $\left(\mathrm{NO}_{\mathrm{X}}\right)$, carbon monoxide (CO), carbon dioxide, oxygen and THC emissions and the wet concentration of unburned hydrocarbons. A Cambustion DMS 500 differential mobility spectrometer was used to determine the exhaust particle size distribution from 10 to $1000 \mathrm{~nm}$, total mass and number of particles per unit volume of exhaust gas. The particle density was assumed to be $1.77 \mathrm{~g} / \mathrm{cm}^{3}$ [47].

\subsubsection{Fuel samples investigated}

The samples tested in the engine included raw SCG oil extracted at pilot plant scale from instant SCGs [16], SCG neat biodiesel produced from the same raw SCG sample according to the method described in Section 2.2, neat commercial soya and rapeseed biodiesel, and blends of the aforementioned biodiesel samples with a reference fossil diesel of zero FAME content containing $7 \% \mathrm{v} / \mathrm{v}$ and $20 \% \mathrm{v} / \mathrm{v}$ FAMEs.

\subsubsection{Experimental conditions}

All combustion experiments were conducted at an engine speed of $1200 \mathrm{rpm}$ and 600 bar injection pressure, with the injection duration was adjusted for every fuel sample so that the engine indicated mean effective pressure was always constant at 4 bar. In the experiments with raw SCG oil, the fuel injection pressure was initially increased to 860 bar at constant injection conditions and 940 bar at constant ignition conditions so as to initiate combustion of the sample before decreasing it to measurement conditions ( 600 bar) for the collection of incylinder pressure and exhaust emissions data. Operation of the research engine at a load of 4 bar indicated mean effective pressure represents a common engine load prevailing during passenger vehicle urban driving conditions, while the engine speed of $1200 \mathrm{rpm}$ was somewhat below those found in urban driving conditions, as was the injection pressure of 600 bar. These settings were selected in order to reduce the consumption rate of fuels used in this study, given the laborious process of producing SCG biodiesel.

Each test day was started and ended with a reference diesel fuel test, so as to detect any day to day drift or longer term change in the experimental equipment and instrumentation. The reference diesel tests also provided a measure of the test-to-test repeatability of the exhaust gas emissions. Each of the fuel samples and the reference diesel were tested at two experimental conditions of constant fuel injection timing and constant start of ignition timing. At constant injection timing the start of injection (SOI) was fixed at 5.0 CAD before TDC, and the start of combustion (SOC) for each fuel sample varied depending on the ignition delay of that fuel. Ignition delay was defined as the time between SOI and SOC, while SOC was defined as the time in CAD (after SOI and before the time of peak heat release rate) at which the minimum value of cumulative heat release occurs [22].

For constant ignition timing, the SOI was varied so that the SOC of all fuels always occurred at TDC. All the experiments were conducted with the test fuels maintained at ambient conditions $\left(\sim 30^{\circ} \mathrm{C}\right)$, except for the raw coffee oil which was heated to $45^{\circ} \mathrm{C}$ to avoid solidification. Previous studies have reported that a rise in temperature up to $38^{\circ} \mathrm{C}$ caused only a small decrease in the ignition delay that was of low significance $[35,36]$.

\section{Results and discussion}

\subsection{Transesterification of SCG oil}

\subsubsection{Acid-catalyzed pretreatment}

Fig. 2 shows the FFA content of the pretreated SCG oil against the process duration, with oil samples subjected to esterification at different conditions of temperature, methanol-to-FFA molar ratio and catalyst-to-FFA weight percentage. The standard deviation of each point was found to be 0.26 as calculated from a total of 27 experimental repeats and represents the reproducibility of the obtained results.

It can be seen in Fig. 2(a) and (b) that an increase of process duration from 2 to $4 \mathrm{~h}$ resulted in oil with reduced level of FFAs, regardless of the other experimental conditions, with durations shorter 


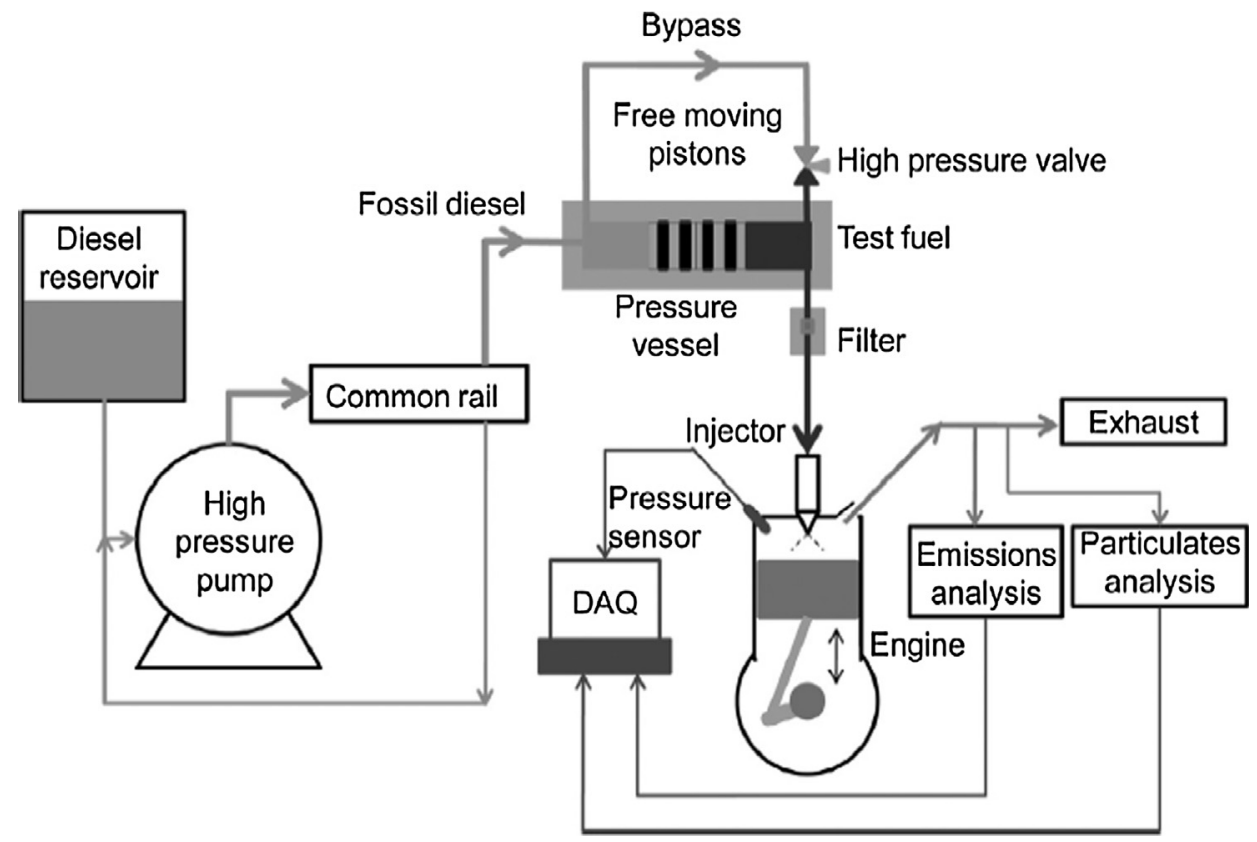

Fig. 1. Schematic showing operation of the low volume fuel system (adapted from Hellier et al. [22].

than $4 \mathrm{~h}$ not sufficient for a successful conversion of FFAs. The temperature of the process also had a significant impact on the efficiency of FFA esterification, with a higher temperature of $60^{\circ} \mathrm{C}$ resulting in pretreated oil with lower FFA content relative to samples esterified at $50{ }^{\circ} \mathrm{C}$.

Regarding the effect of methanol-to-FFA molar ratio on the esterification of FFA, a ratio of 17.8:1 resulted in oil samples with lower FFA content compared to those esterified at a molar ratio of $13: 1$, with a further increase to 22.5:1 slightly improving the efficiency of the process, indicating that overly excessive amounts of methanol do not significantly enhance the esterification reaction. A comparison between Fig. 2(a) and (b) shows that the use of a higher percentage of catalyst relative to FFAs led to oil samples with slightly reduced FFA contents. In general, the effect of methanol-to-FFA molar ratio on the conversion of FFAs during esterification process was found to be more crucial than that of sulfuric acid quantity within the range of investigated conditions.

The weight loss of pretreated SCG oil relative to initial untreated oil weight was found to be $1.31 \pm 0.73 \% \mathrm{w} / \mathrm{w}$ when the process was carried out at optimal conditions, likely attributable to the process of
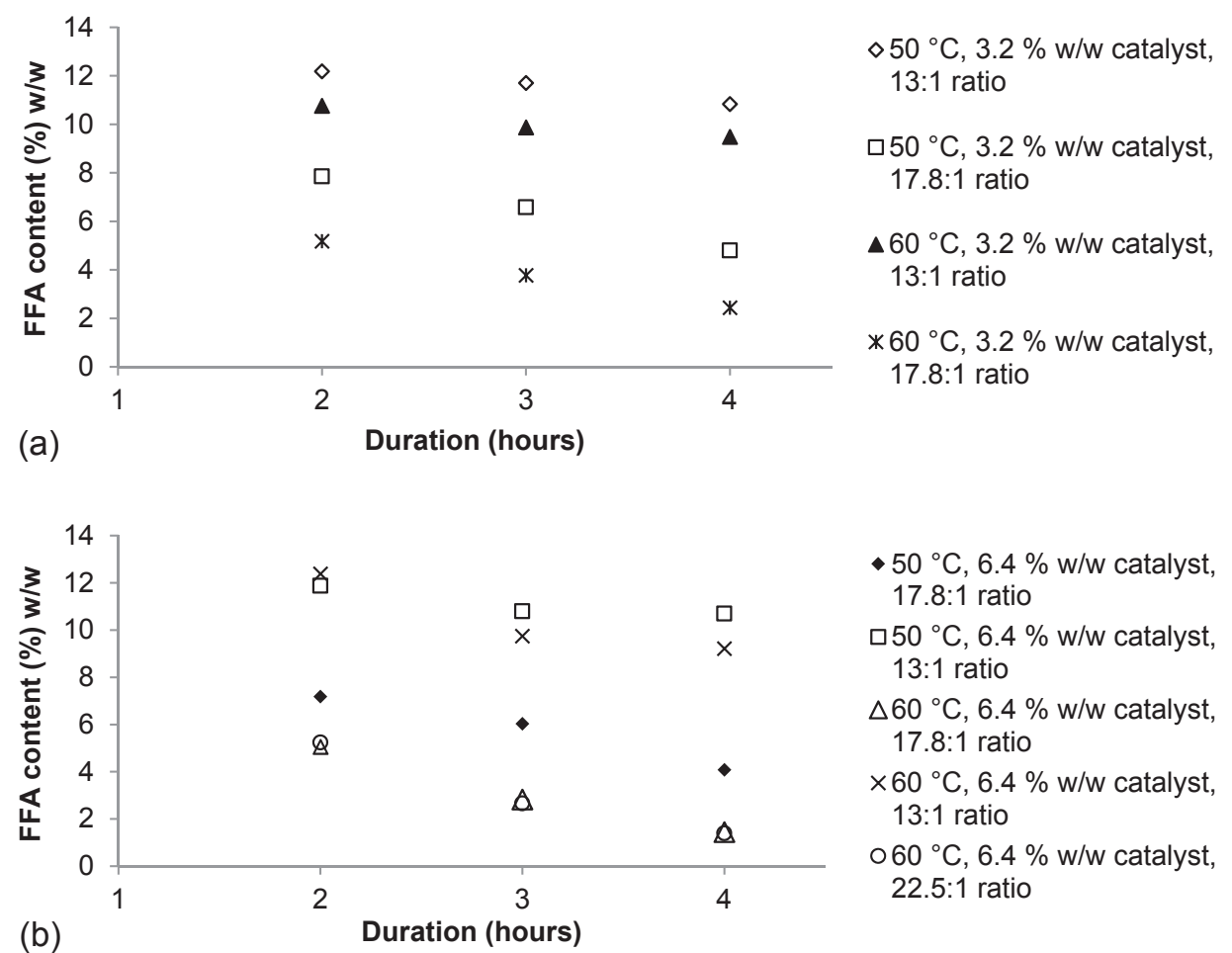

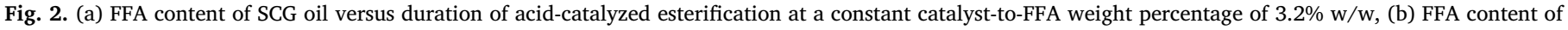
SCG oil versus duration of acid-catalyzed esterification at a constant catalyst-to-FFA weight percentage of $6.4 \% \mathrm{w} / \mathrm{w}$. 


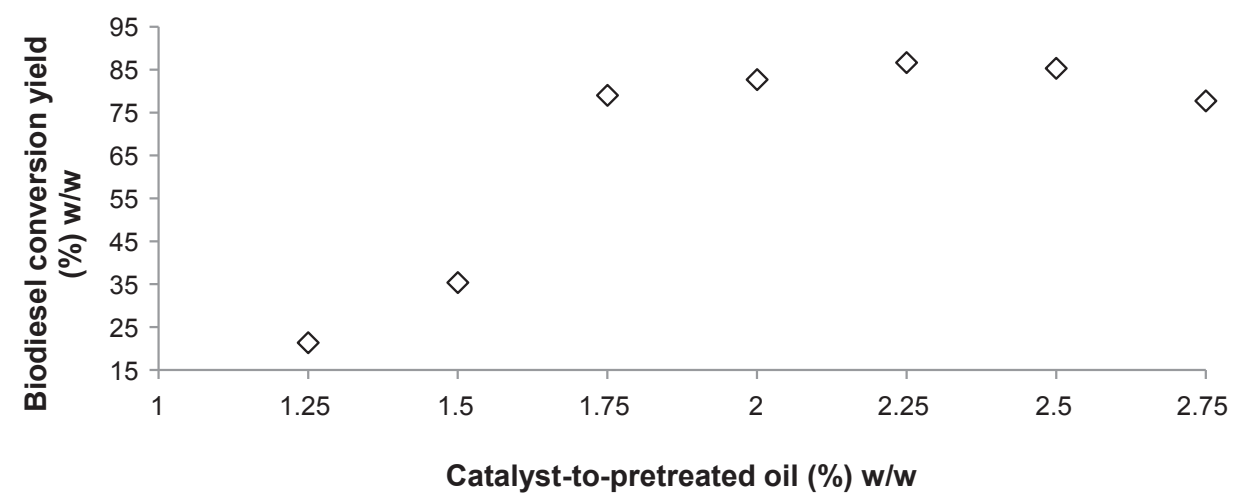

Fig. 3. Base-catalyzed transesterification reaction yields against catalyst-to-pretreated oil weight percentage.

separating the excess methanol and water from the mixture, as small amounts of unreacted triglycerides and methyl esters can dissolve in the methanol and water mixtur $[8,37]$.

\subsubsection{Base-catalyzed transesterification}

Base-catalyzed transesterification experiments were performed with SCG oil previously subjected to acid-catalyzed esterification, with FFA content of $1.44 \pm 0.26 \% \mathrm{w} / \mathrm{w}$. The density of the pretreated oil was found to be $0.915 \mathrm{~g} / \mathrm{ml}$. Fig. 3 shows the effect of varying catalyst-topretreated oil weight percentage on the $\% \mathrm{w} / \mathrm{w}$ reaction yield expressed relative to pretreated oil weight, when the base-catalyzed transesterification was performed at a constant methanol-to-pretreated oil molar ratio of 9:1. The standard deviation of each point was found to be 0.47 as calculated by a total of 9 experimental repeats.

It can be seen in Fig. 3 that potassium hydroxide weight percentages up to $1.5 \% \mathrm{w} / \mathrm{w}$ of the pretreated oil were not sufficient for successful conversion of oil into FAMEs, achieving low reaction yields due to neutralization of the catalyst by unreacted acids. However, an increase of the catalyst percentage to $1.75 \% \mathrm{w} / \mathrm{w}$ resulted in significant increase of the conversion rate, with further increase to $2.25 \% \mathrm{w} / \mathrm{w}$ resulting in the highest reaction yield of $86.66 \% \mathrm{w} / \mathrm{w}$. Catalyst percentages higher than $2.25 \% \mathrm{w} / \mathrm{w}$ led to a slight decrease of the reaction yield, potentially due to soap formation by the reaction of triglycerides with $\mathrm{KOH}$, that reduced conversion rate and inhibited the separation of FAMEs from glycerol $[14,40]$.

The optimal percentage of catalyst to pretreated oil weight was slightly higher than those reported in previous studies, which ranged between $0.5 \% \mathrm{w} / \mathrm{w}$ and $1.5 \% \mathrm{w} / \mathrm{w}$ of the lipid weight $[2,12,19,38,59]$. This difference can possibly be attributed to the level of unreacted FFAs present in the oil after the esterification pretreatment, which was higher than FFA levels of SCG oil samples in the aforementioned studies, thus requiring slightly higher catalyst amount.

Fig. 4 shows the effect of varying methanol-to-pretreated oil molar ratio on the efficiency of the base-catalyzed transesterification process. The experiments with different methanol-to-pretreated oil molar ratios were performed at a constant catalyst-to-pretreated oil weigh percentage of $2.25 \% \mathrm{w} / \mathrm{w}$, and the error bars shown represent the reproducibility of the obtained results.

It can be seen in Fig. 4 that an increase of the methanol-to-pretreated oil molar ratio from 9.0:1 to 13.5:1 resulted in a slight increase of the process reaction yield, with a further increase in molar ratio to 18.0:1 having an insignificant effect on the efficiency of base-catalyzed transesterification at the investigated conditions of duration, temperature and catalyst-to-oil weight percentage. The relationship found between methanol-to-oil molar ratio and reaction yield is in good agreement with previous studies that performed base-catalyzed transesterification of vegetable oils, which reported that increase of methanol-to-oil molar ratio above an optimal value had little effect on the reaction yield $[40,60]$. The slight increase of reaction yield with an increase of the methanol-to-oil molar ratio to $13.5: 1$ can possibly be attributed to a decrease of pretreated oil viscosity due to increased alcohol quantity, which resulted in increased oil solubility in methanol and consequently higher FAME yield [14].

A comparison of the reaction yields obtained relative to catalyst-topretreated oil weight percentage and methanol-to-pretreated oil molar ratio presented in Figs. 3 and 4 respectively, suggests that the amount of catalyst relative to oil weight has a more important effect on the efficiency of the process than the methanol-to-oil ratio within the investigated range. The relatively lower reaction yield obtained relative to previous studies that investigated base-catalyzed transesterification of SCG oil $[1,12,38,59]$, can potentially be attributed to the FFA content of the pretreated oil that may have inhibited complete conversion into FAMEs, and to the high methanol-to-oil molar ratios used which possibly enhanced emulsion formation and hindered the separation of FAMEs from water [14].

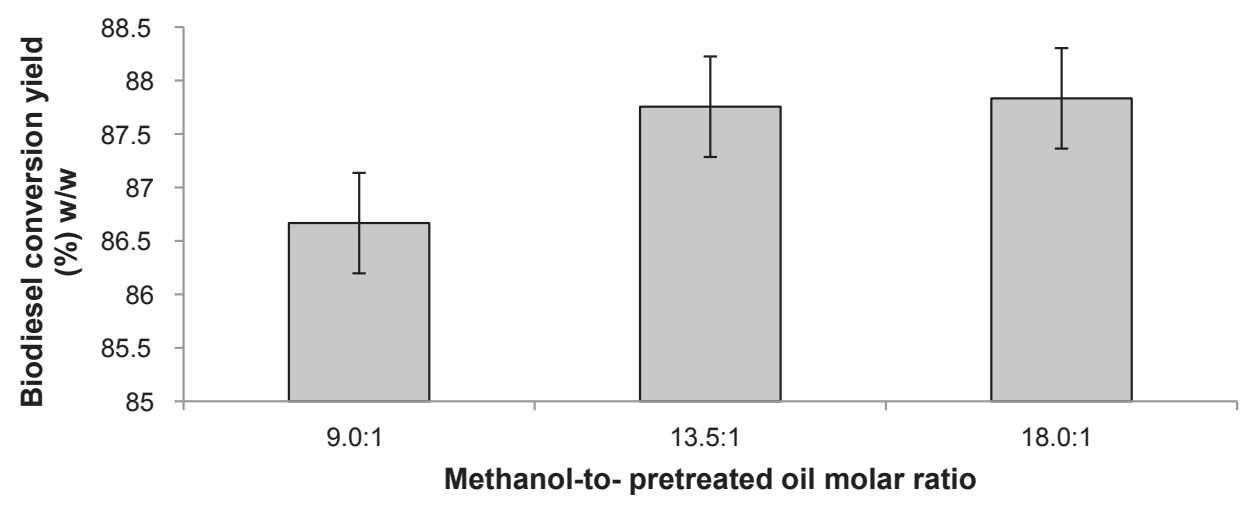

Fig. 4. Base-catalyzed transesterification reaction yield against methanol-to-pretreated oil molar ratio. 


\subsubsection{SCG oil and biodiesel properties}

Table 2 shows the fatty acid profile and properties of obtained SCG biodiesel, along with those of soya and rapeseed biodiesel which were also tested in subsequent engine experiments for comparison purposes (Section 3.2). Table 2 also shows the properties of the reference fossil diesel and the generally applicable diesel quality requirements according to European standard EN 14214 [4].

It can be seen in Table 2 that the main fatty acid esters in the SCG biodiesel are linoleic (C18:2), palmitic (C16:0), oleic (C18:1) and stearic (C18:0), with lower quantities of $\gamma$-linolenic (C18:3n6) and $\alpha$ linolenic (C18:3n3) in decreasing order of magnitude. Small variations were found in the percentages of the fatty acids present in SCG biodiesel samples transesterified at different conditions, suggesting that the transesterification process, and in particular the varying methanol-topretreated oil molar ratio of the base-catalyzed step, did not have a significant and systematic effect on the fatty acid profile of the resulting SCG biodiesel. In all the examined samples, a small mass percentage was not coupled with specific FAMEs, however unidentified peaks had similar retention times to the FAMEs detected suggesting that they are plausibly similar compounds.

The density of the SCG biodiesel mixture was found to be slightly higher than the densities of soya and rapeseed FAMEs but within the standard EN 14214 limits [4]. In addition, the density of SCG biodiesel was lower than that of untreated SCG oil which was found to be $0.927 \mathrm{~g} / \mathrm{cm}^{3}$, and similar to that of SCG biodiesel samples reported in previous studies (Table 1). The acid value of SCG was found to be slightly higher than the standard EN 14214 limit [4], and can potentially be attributed to incomplete transesterification due to the relatively high FFA content of the acid-catalyzed pretreated oil.

The KV of the SCG biodiesel was significantly reduced relative to that of raw SCG oil which was found to be $45.7 \mathrm{~mm}^{2} / \mathrm{s}$, but greater than that of soya and rapeseed biodiesel and above the standard EN 14214 biodiesel limit [4]. SCG biodiesel has relatively higher levels of C16:0 than the other biodiesel samples, but less C18:1 (Table 2), and consequently based on its fatty acid profile its KV should not have been significantly different that those of soya and rapeseed biodiesel samples if it was solely comprised of FAMEs [32]. The higher measured KV of SCG biodiesel can possibly be attributed to an incomplete transesterification reaction and/or inefficient purification process that might have resulted in a relatively high presence of free glycerol, non-transesterified glycerides and FFAs in the sample.

The HHV of SCG biodiesel was found to be higher than that of SCG oil $(39.05 \pm 0.15 \mathrm{MJ} / \mathrm{kg})$ and similar to SCG biodiesel HHVs measured in previous studies (Table 1). The HHVs of soya and rapeseed FAMEs were slightly higher than that of SCG biodiesel, possibly attributable to their longer average chain length, due to the higher presence of C18 chains in soya and rapeseed FAMEs compared to SCG FAMEs.

Another important parameter for the quality of biodiesel that is not presented in Table 2 is cetane number (CN), which is an indicator of fuel ignition quality in diesel engines and is related to the ignition delay time, with shorter ignition delay time typically translated into higher CN $[31,48]$. The CNs of the biodiesel samples used in this study were estimated based on their identified FAME components, which ranged from 98.4 to $98.9 \% \mathrm{w} / \mathrm{w}$ of the totals samples (Table 2), according to Eq. (4) $[54,61]$. The calculated CNs corresponding to each FAME can be found in Table S.1 of the Supplementary Material section.

$C N=\sum_{\mathrm{i}=1}^{\mathrm{n}} \frac{\% w_{i}}{100} \times \mathrm{CN}_{\mathrm{i}}$

where $w_{i}$ is the mass percentage of each of the identified FAMEs and $\mathrm{CN}_{\mathrm{i}}$ the corresponding FAME cetane number. The CNs of the SCG, soya and rapeseed biodiesel samples were estimated to be 60.8, 53 and 57 respectively, nevertheless this calculation is intended to offer an indication and should not be taken as an absolute $\mathrm{CN}$ measurement. The calculated CN of SCG biodiesel is similar to that found by Vardon et al. 

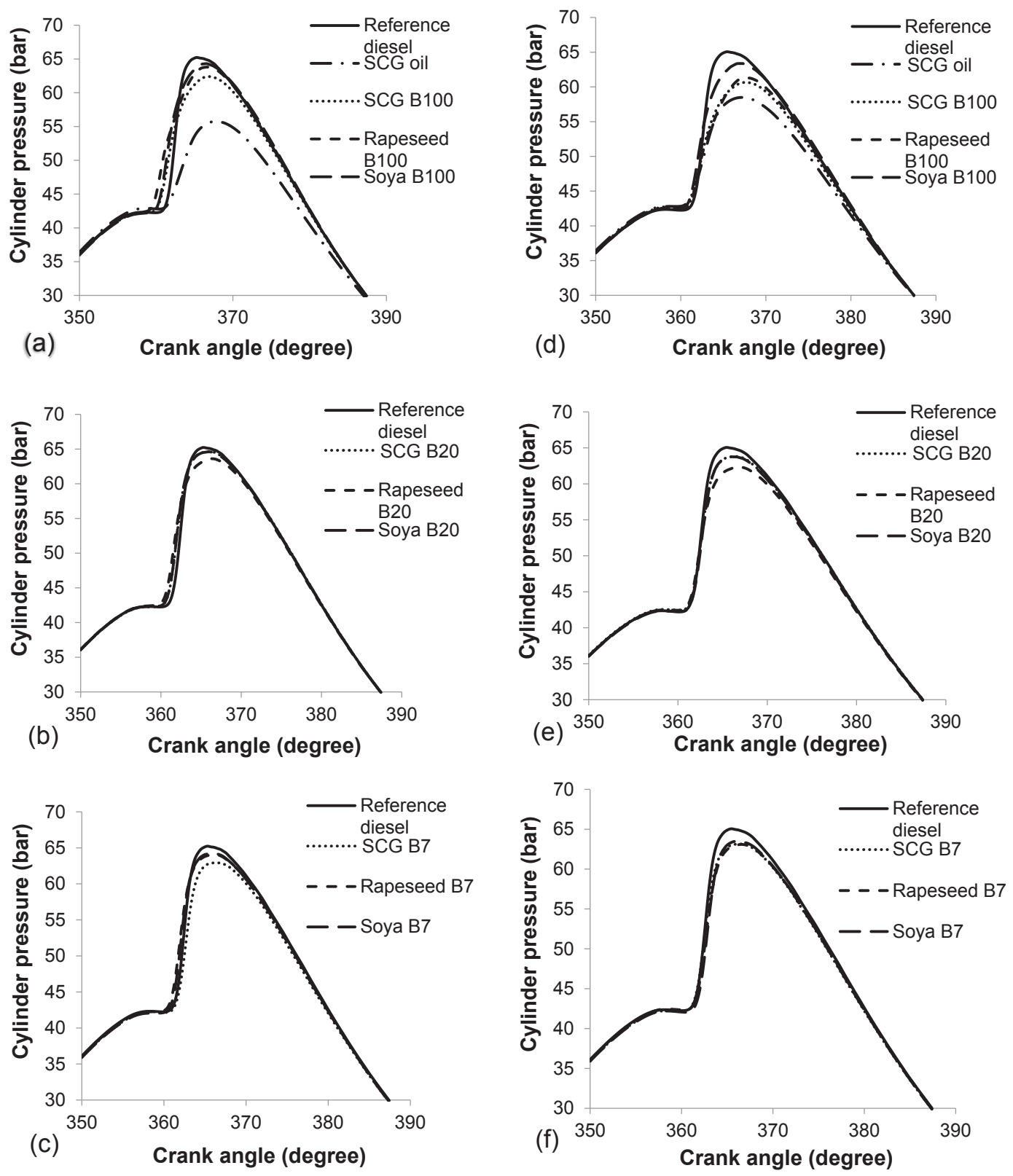

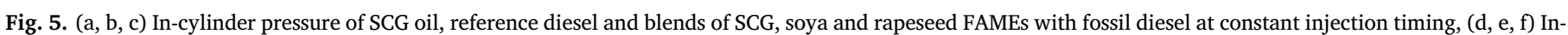
cylinder pressure of SCG oil, reference diesel and blends of SCG, soya and rapeseed FAMEs with fossil diesel at constant ignition timing.

[59], who reported a value of 60.1 for neat SCG biodiesel, whereas the estimated $\mathrm{CN}$ values for the commercial soya and rapeseed FAMEs are slightly higher than the originally measured $\mathrm{CNs}$ which were known to be 52 for both samples. This increase of $\mathrm{CN}$ relative to original value can be possibly attributed to a partial oxidation of the soya and rapeseed FAME samples due to prolonged storage [43]. The higher CN of SCG biodiesel relative to soya and rapeseed FAMEs can be explained by its lower degree of unsaturation [9,48], which is expressed in Table 2 through the average number of double bonds. It is also interesting to note that the minimum required CN limit is 51 [4].

\subsection{Combustion experiments}

Fig. 5 shows the engine in-cylinder pressure during combustion of the various fuel samples and reference diesel at constant injection and constant ignition timing conditions.

It can be seen in Fig. 5 that reference fossil diesel achieved the highest peak pressure of all samples tested, potentially due to a larger amount of premixed fuel prior to ignition and hence a greater rate of initial heat release close to TDC. Raw SCG oil and neat SCG biodiesel developed lower peak in-cylinder pressures, likely attributable to reduced air mixing and subsequent lower rates of combustion resulting from poor fuel atomisation, due to the high KV of raw SCG oil, and the relatively high KV of the neat SCG biodiesel compared to other biodiesel samples (Table 2). It can also be seen in Fig. 5(a) that neat rapeseed biodiesel ignited earlier than the other samples at conditions of constant injection timing. In general, Fig. 5 shows that the reduction in the amount of FAME present in the biodiesel and fossil diesel blends generally resulted in higher peak in-cylinder pressures.

Fig. 6 shows the apparent net heat release rate of neat and blended SCG, soya and rapeseed FAMEs, SCG oil and reference diesel at constant injection and constant ignition timing conditions.

It can be seen in Fig. 6 that for all the samples used, the apparent HRR reduced to values below zero just before ignition due to the fuel spray absorbing energy (enthalpy of vaporization) from the in-cylinder air to form the vapour/air mixture that subsequently ignited. In the case 

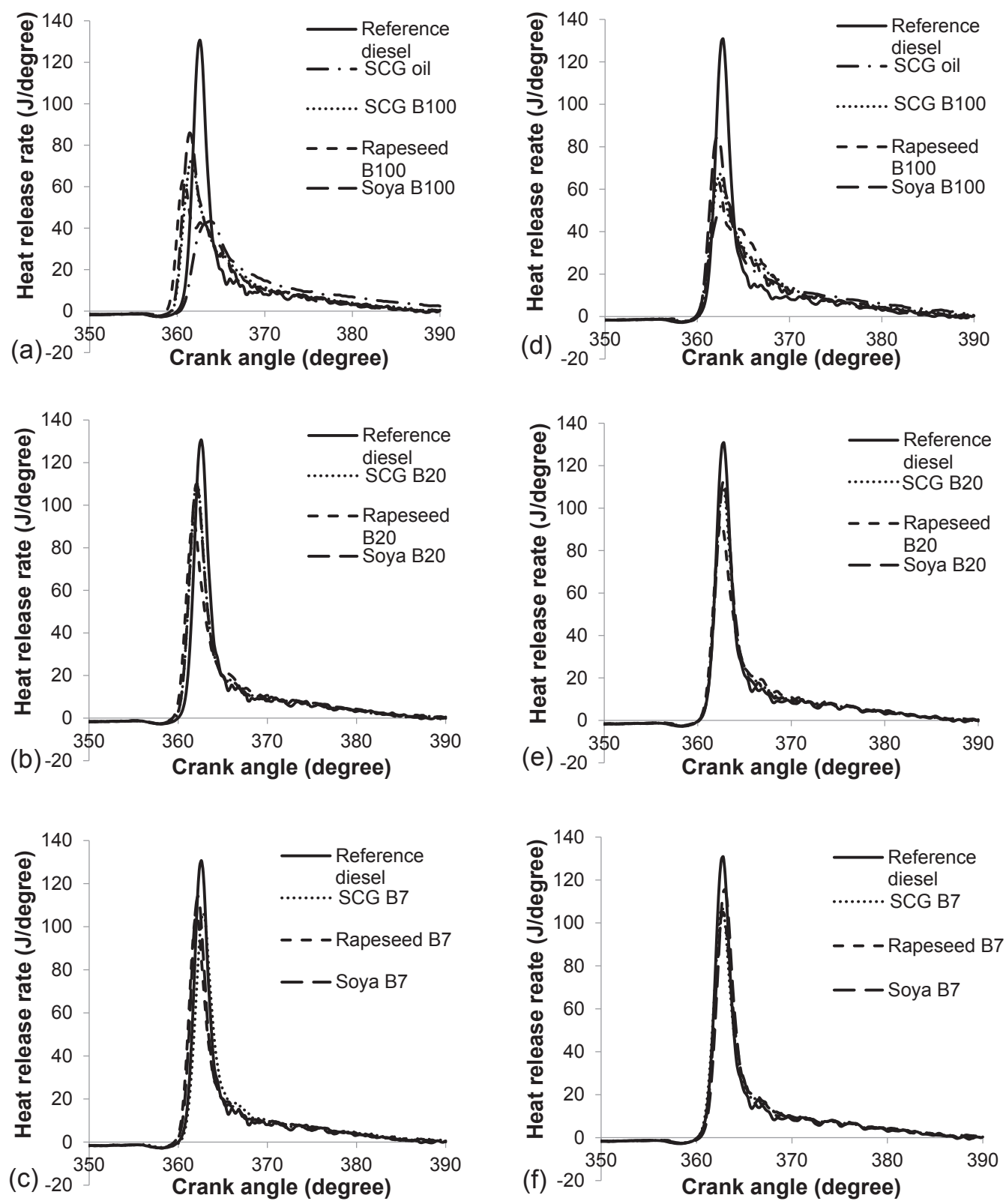

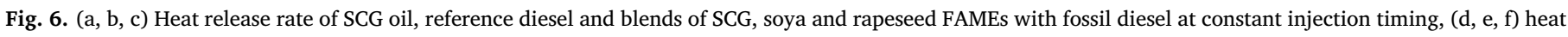
release rate of SCG oil, reference diesel and blends of SCG, soya and rapeseed FAMEs with fossil diesel at constant ignition timing.

of reference fossil diesel and biodiesel blends, the majority of heat release occurred during premixed combustion, defined as the combustion of fuel and air that are mixed to combustible stoichiometry during the ignition delay period [22], as signified by the rapid rise of heat release rates following SOC.

The significant change in the slope of the curves after premixed combustion, which occurred at $365 \mathrm{CAD}$ in the case of fossil reference diesel (Fig. 6(a) and (d)) indicates that the premixed amount of fuel/air mixture had been consumed and signals the transition of the combustion mode from premixed to diffusion burning dominated. Fuels with small premixed amount of fuel have more of the injected fuel burning in the diffusion-combustion mode, as is the case with the neat SCG biodiesel, possibly due to lower rates of air-fuel mixing.

Fig. 7(a) and (b) show the ignition delay of the various samples used in the engine experiments against their biodiesel content, where $0 \% \mathrm{v} / \mathrm{v}$ biodiesel is pure reference fossil diesel, at constant injection and constant ignition timing conditions respectively.

It can be seen in both Fig. 7(a) and (b) that the neat biodiesel samples exhibited the shortest duration of ignition delay of all the samples tested, while reference fossil diesel and raw SCG oil had the longest delays. Also apparent is that in the case of all three varieties of FAMEs tested (SCG, soya, rapeseed), an increase of the biodiesel content from $7 \% \mathrm{v} / \mathrm{v}$ to $100 \% \mathrm{v} / \mathrm{v}$ resulted in a decrease in the ignition delay time at both timing conditions. In general, FAMEs tend to have shorter ignition delay relative to fossil diesel due to the presence of long alkyl carbon chains which can undergo hydrogen abstraction and break down more easily than some of the molecules present in fossil diesel (e.g. aromatic molecules, isomers and napthenes in diesel are more difficult to ignite than the long alkyl chains of FAMEs) [33]. In addition, the aromatic molecules in fossil diesel can have hydrogen abstracted but subsequently absorb radicals to re-stabilize and thus reduce the radical pool which would otherwise accelerate the process of ignition.

Long ignition delays have been associated with low fuel CN numbers and high degree of FAME unsaturation [9,48]. Therefore, and drawing conclusions from the fatty acid profiles of SCG, soya and rapeseed biodiesel presented in Table 2, the soya and rapeseed FAMEs 

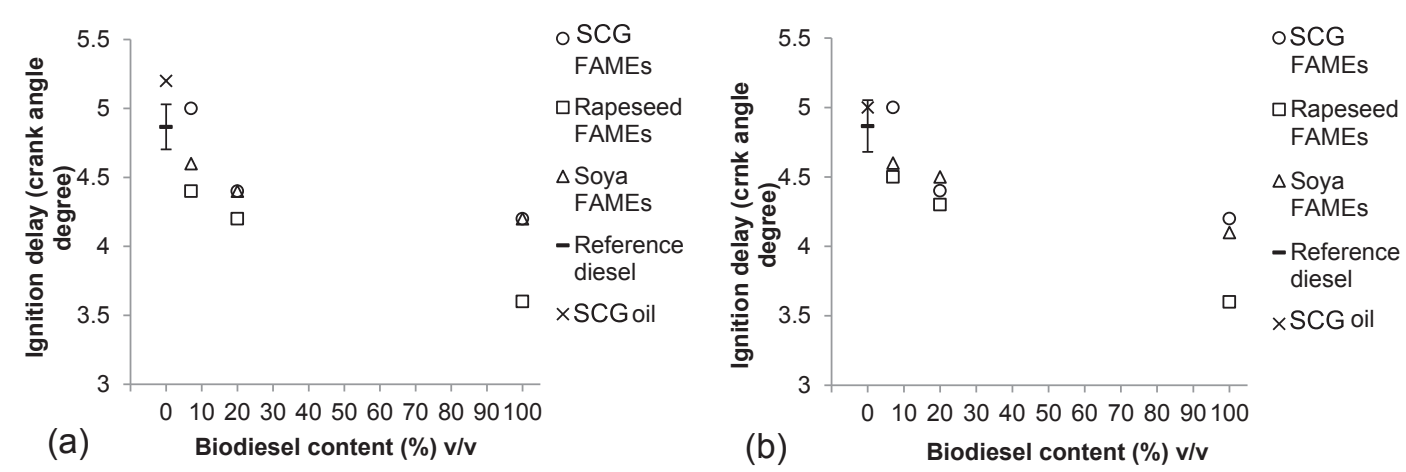

Fig. 7. (a) Ignition delay against biodiesel content at conditions of constant injection timing, $(\sigma=0.16)$. (b) Ignition delay against biodiesel content at conditions of constant ignition timing, $(\sigma=0.18)$.

might have been expected to exhibit longer ignition delays compared to SCG FAMEs which were more saturated, something that is also supported by the calculated CNs of the examined biodiesel samples (Section 3.1.3). However, it can be seen in Fig. 7(a) and (b) that SCG biodiesel exhibits a longer ignition delay than the rapeseed FAME blends, and equivalent or longer ignition delay than the soya FAME blends despite having a higher calculated $\mathrm{CN}$ of 60.8 . This can potentially be attributed to the higher KV of the SCG biodiesel which may have caused a longer ignition delay due to prolonged fuel vaporization and formation of the fuel vapour and air mixture [9]. This hypothesis is also supported by the long ignition delay of the viscous raw SCG oil.

Furthermore, while the SCG FAMEs possess a greater proportion of fully saturated components, the average alkyl chain length of the soya and rapeseed esters is slightly longer (Table 2). In addition, the higher presence of longer chain C18 FAMEs in rapeseed and soya biodiesel relative to SCG biodiesel (Table 2) can contribute to a shorter ignition delay $[9,20,48]$.

Fig. 8(a) and (b) show the peak heat release rate (PHRR) of the samples used in combustion experiments against the biodiesel content at conditions of constant injection and constant ignition timing respectively.

It can be seen in both Fig. 8(a) and (b) that reference fossil diesel displayed the highest PHRR of all samples at both timing conditions, and raw SCG oil the lowest. The PHRRs of the neat and blended biodiesel samples were found to be in between those of fossil diesel and SCG oil, with neat biodiesel having a significantly lower PHRR relative to the blended samples (Fig. 8).

PHRR and ignition delay are closely related and it has been previously observed that increased ignition delay time allows more time for fuel and air mixing prior to ignition, resulting in a larger premixed combustion fraction and therefore higher PHRR [21]. In the case of the reference diesel, the high PHRR observed might also be attributable to the presence of volatile components absent from biodiesel samples, which combined with the long ignition delay, helped form a large amount of premixed fuel/air mixture that then burned rapidly once ignition occurred. However, raw SCG oil displays a low PHRR despite a long ignition delay duration similar to that of reference fossil diesel (Fig. 7), suggesting that ignition delay is not the only limiting factor on the rate of fuel and air mixing. The low PHRR of the raw SCG oil can therefore possibly be attributed to its high KV (Table 2), which potentially inhibits the fuel and air mixing during the ignition delay period, thus reducing the extent of the premixed fuel fraction and consequently the PHRR.

Fig. 9(a) and (b) show the exhaust gas $\mathrm{NO}_{\mathrm{x}}$ emissions of the various fuel samples and reference fossil diesel at constant injection and constant ignition timings respectively.

Fig. 9(a) and (b) show that at both timing conditions raw SCG oil emitted significantly lower levels of $\mathrm{NO}_{\mathrm{x}}$ relative to all the other investigated fuel samples. Reference fossil diesel and neat soya biodiesel emitted the highest $\mathrm{NO}_{\mathrm{x}}$ levels of all fuel samples, while SCG biodiesel emitted the lowest of all the biodiesel samples at both timing conditions.

Production of $\mathrm{NO}_{\mathrm{x}}$ in compression ignition engines is primarily caused by the oxidation of nitrogen present in the intake air, with the reaction rate mainly dependent on in-cylinder temperature and residence time of the cylinder at elevated temperatures [44,53,57]. Consequently, the level of $\mathrm{NO}_{\mathrm{x}}$ emissions is also a function of the duration of ignition delay, as the subsequent in-cylinder temperature conditions are influenced by the extent of premixed burn fraction and the rates of peak heat release [20]. Despite exhibiting the longest ignition delay of all the samples tested (Fig. 7(a) and (b)), the low NOx emissions of raw SCG oil are in agreement with the low peak heat release rates observed in Fig. 8(a) and (b) and can be attributed to poor mixing of air and fuel and incomplete burning.

A relationship between ignition delay and $\mathrm{NO}_{\mathrm{x}}$ emissions is also not readily apparent in the case of the neat and blended biodiesel samples,
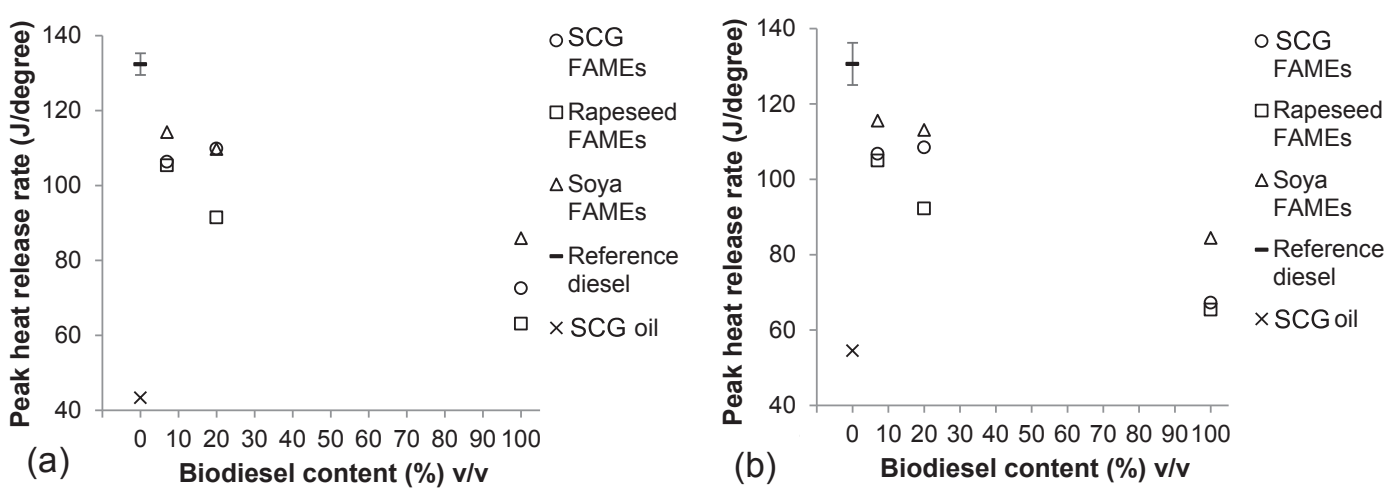

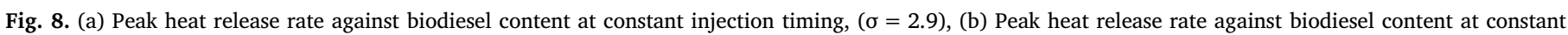
ignition timing, $(\sigma=5.6)$. 

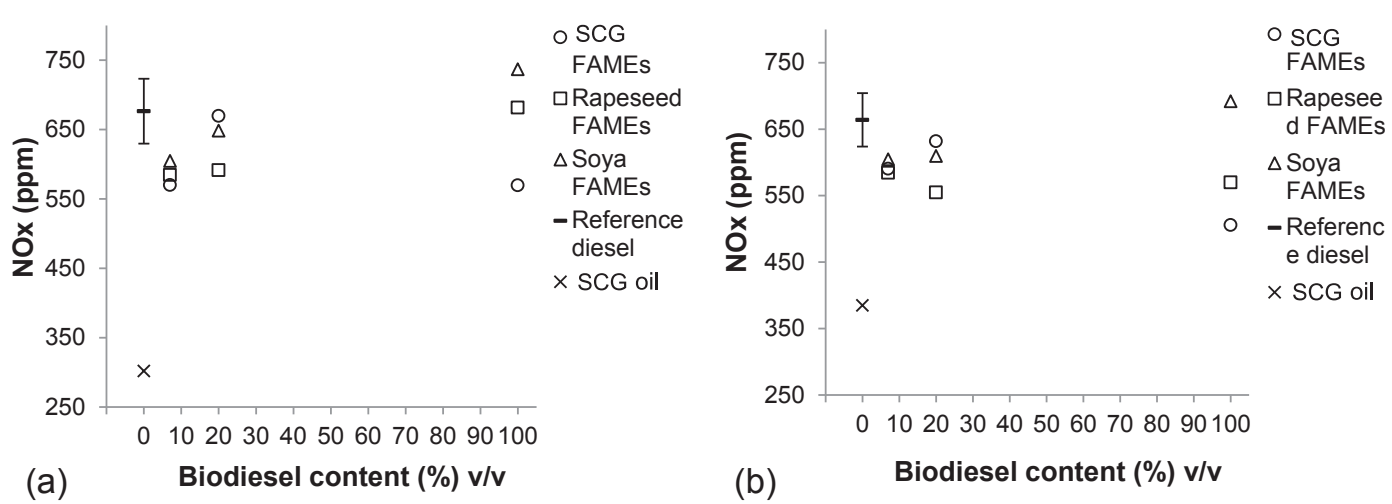

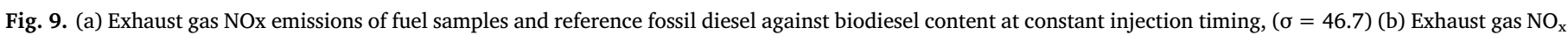
emissions of fuel samples and reference fossil diesel against biodiesel content at constant ignition timing, $(\sigma=40.2)$.

with shorter ignition delays generally resulting in increased $\mathrm{NO}_{\mathrm{x}}$ emissions, suggesting that the quality of combustion is not dominated by ignition delay but by the progressive replacement of fossil diesel with biodiesel. This can possibly be explained by the long alkyl chains of the FAME samples when compared to diesel molecules, such as the aromatics, isomers and napthenes. Furthermore, the presence of oxygen in FAME molecules can also result in relatively high $\mathrm{NO}_{\mathrm{x}}$ emissions compared to fossil diesel [55], while biodiesel flames do not radiate as much energy due to a reduced presence of particulates that decrease radiative heat transfer, leading to higher actual flame temperature and a corresponding $\mathrm{NO}_{\mathrm{x}}$ increase [44].

In addition, the production of $\mathrm{NO}_{\mathrm{x}}$ exhaust gases from FAMEs is known to increase with higher degree of unsaturation and decreasing chain length due to increasing adiabatic flame temperature [20,30,48], and therefore the high levels of $\mathrm{NO}_{\mathrm{x}}$ emissions observed when rapeseed and soya FAMEs were used can be partly attributed to the high degree of unsaturation of these samples (Table 2). Combustion of SCG biodiesel, resulted in the emission of a lower amount of $\mathrm{NO}_{\mathrm{x}}$ gases relative to the other neat biodiesel samples, in agreement with Mueller et al. [44] who reported that higher cetane fuels (Table 2) tend to produce lower $\mathrm{NO}_{\mathrm{x}}$ emissions.

Figs. 10(a)-(b) and 11(a)-(b) show the CO and THC emissions of the various fuel samples and reference fossil diesel at conditions of constant injection and constant ignition timing.

It can immediately be seen in Figs. 10 and 11 that raw SCG oil emitted very high levels of $\mathrm{CO}$ and THC relative to the other fuel samples tested. This observation, in conjunction with the low $\mathrm{NO}_{\mathrm{x}}$ emissions produced when raw SCG oil was used as a fuel (Fig. 9), further verifies the hypothesis that the SCG oil did not mix well with air, resulting in incomplete burning, as both $\mathrm{CO}$ and THC are known products of incomplete combustion [24].

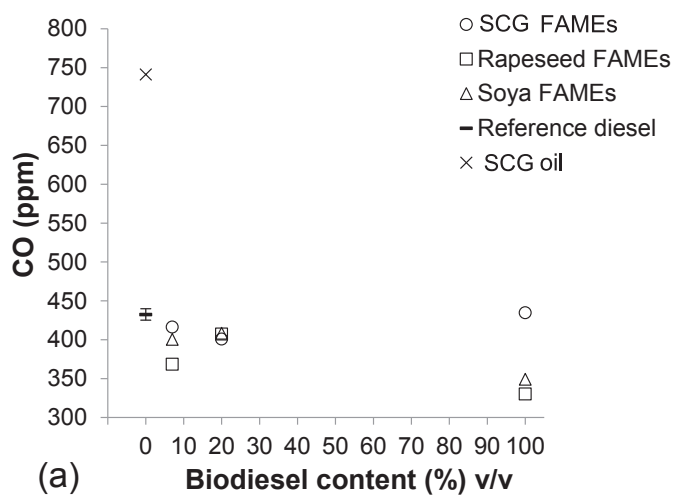

Furthermore, the CO emissions of neat and blended soya and rapeseed biodiesel show an overall tendency to decrease when the biodiesel content of the sample increased and the ignition delay decreased (Fig. 7(a) and (b)), while THC emissions tended to increase especially in the case of soya FAMEs. A greater fraction of SCG biodiesel in the fuel sample resulted in higher emissions of $\mathrm{CO}$ and THC in most cases. This observation, along with the relatively high $\mathrm{CO}$ and THC emissions produced when neat SCG biodiesel was used at both timing conditions, suggests that the high KV of SCG biodiesel caused inefficient air-fuel mixing.

Fig. 12 shows the particulate emissions of the tested fuel samples and reference fossil diesel at constant injection and constant ignition timings.

Fig. 12 shows that neat SCG biodiesel and raw SCG oil emit a much higher number of particles relative to the other fuel samples used at both conditions of constant injection and constant ignition timing. Fig. 12(a) shows that raw SCG oil resulted in the production of a much higher number of particles greater than $50 \mathrm{~nm}$ in diameter relative to neat SCG biodiesel at conditions of constant injection timing, while both samples produced a similar number of particulates between 10 and $1000 \mathrm{~nm}$ when the experiments were performed at conditions of constant ignition timing.

This high amount of particulates produced from raw SCG oil is possibly a consequence of poor fuel atomization, attributable to the high KV of the oil, and incomplete burning conditions, as suggested by the elevated emissions of CO and THC (Figs. 10 and 11), while the relatively low rates of heat release allowed more time for the continued production and agglomeration of smaller particles into large ones. The significantly higher amount of particulates produced by the combustion of neat SCG biodiesel relative to other biodiesel samples can similarly be partly attributed to the higher KV of this sample, however, this alone

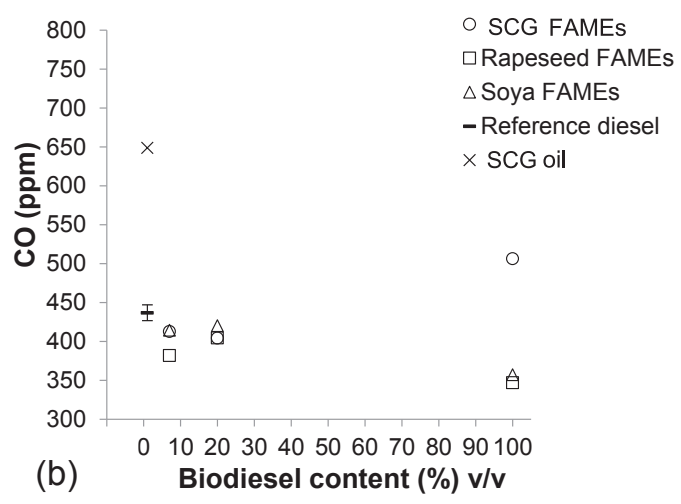

Fig. 10. (a) CO emissions against biodiesel content at constant injection timing, ( $\sigma=7.3$ ), (b) CO emissions against biodiesel content at constant ignition timing, $(\sigma=10.1)$. 

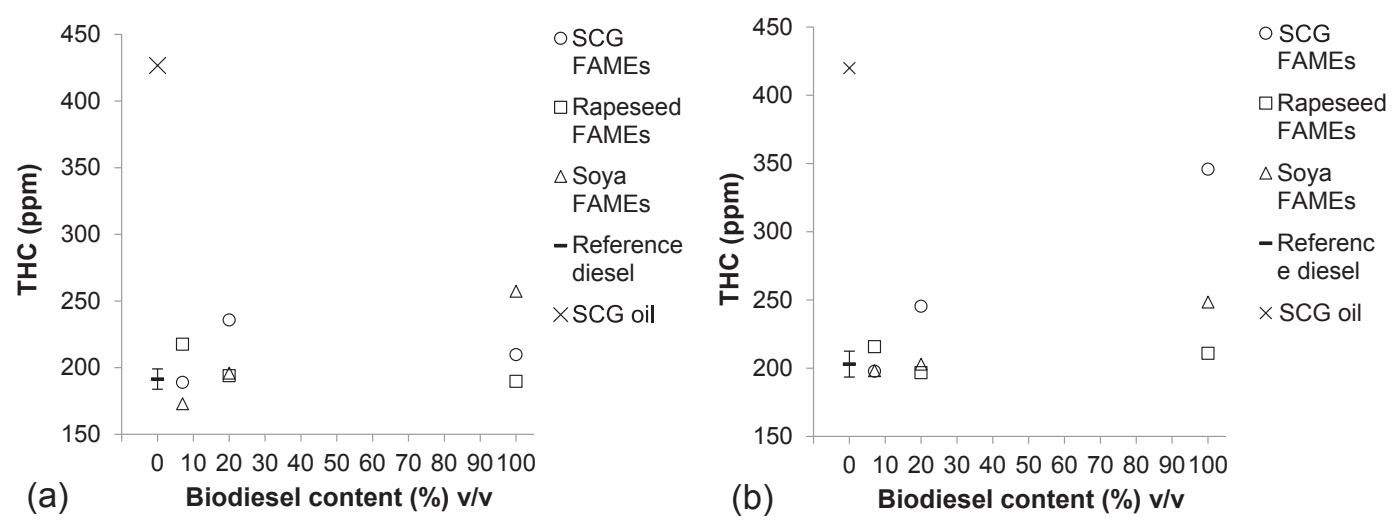

Fig. 11. (a) THC emissions against biodiesel content at constant injection timing, $(\sigma=7.6)$, (b) THC emissions against biodiesel content at constant ignition timing, $(\sigma=9.5)$.
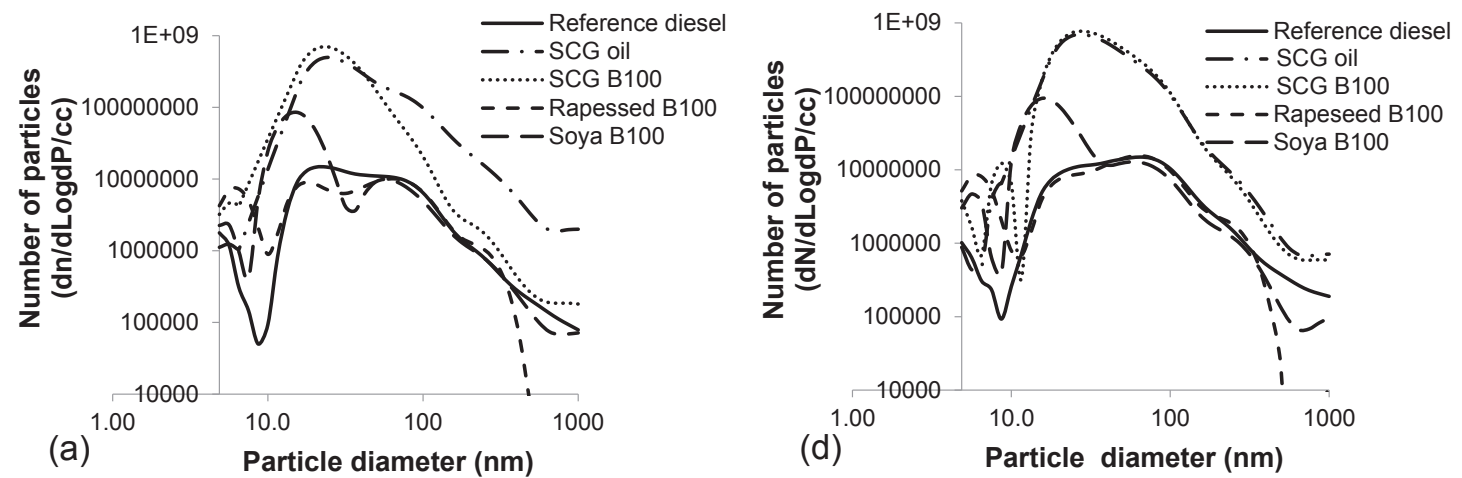

(d)

Particle diameter (nm)
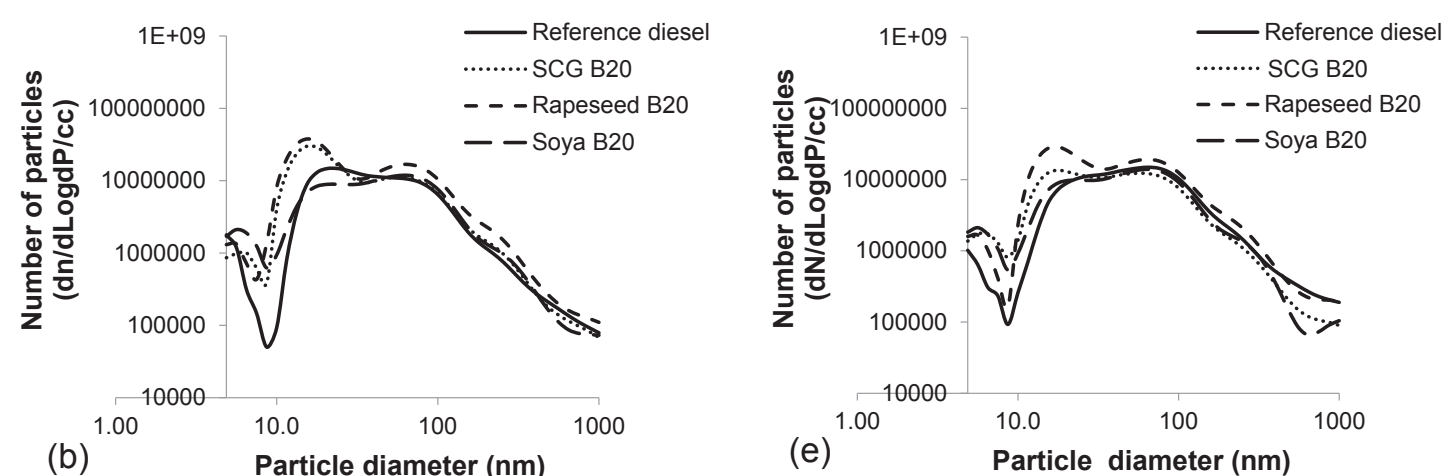

(e)

Particle diameter (nm)
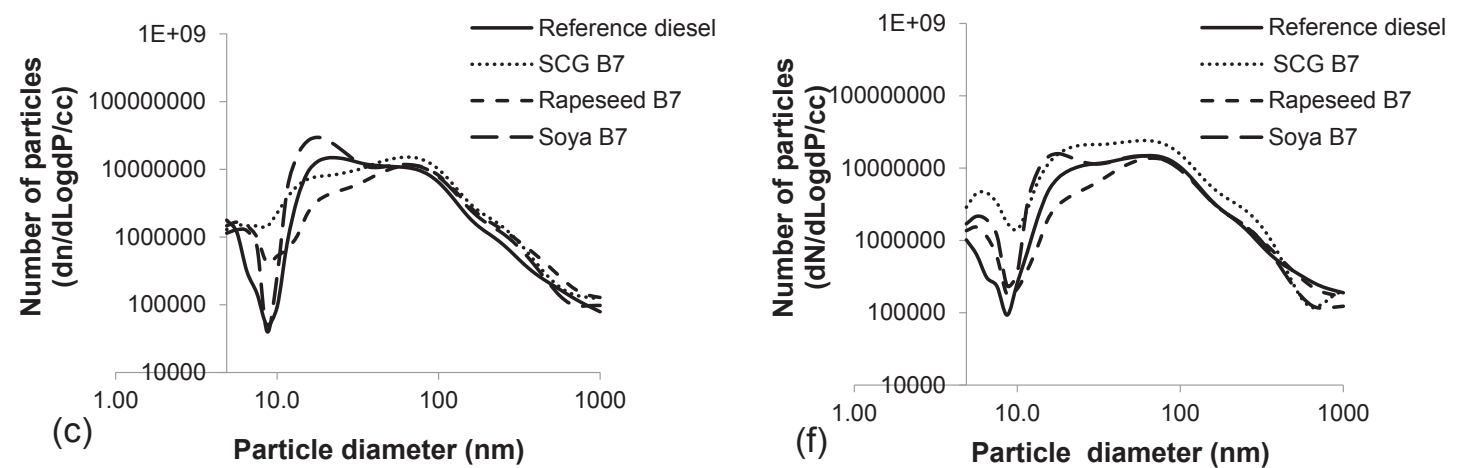

Fig. 12. (a, b, c) Particulate emissions of SCG oil, reference diesel and blends of SCG, soya and rapeseed FAMEs with fossil diesel at constant injection timing, (d, e, f) Particulate emissions of SCG oil, reference diesel and blends of SCG, soya and rapeseed FAMEs with fossil diesel at constant ignition timing. 

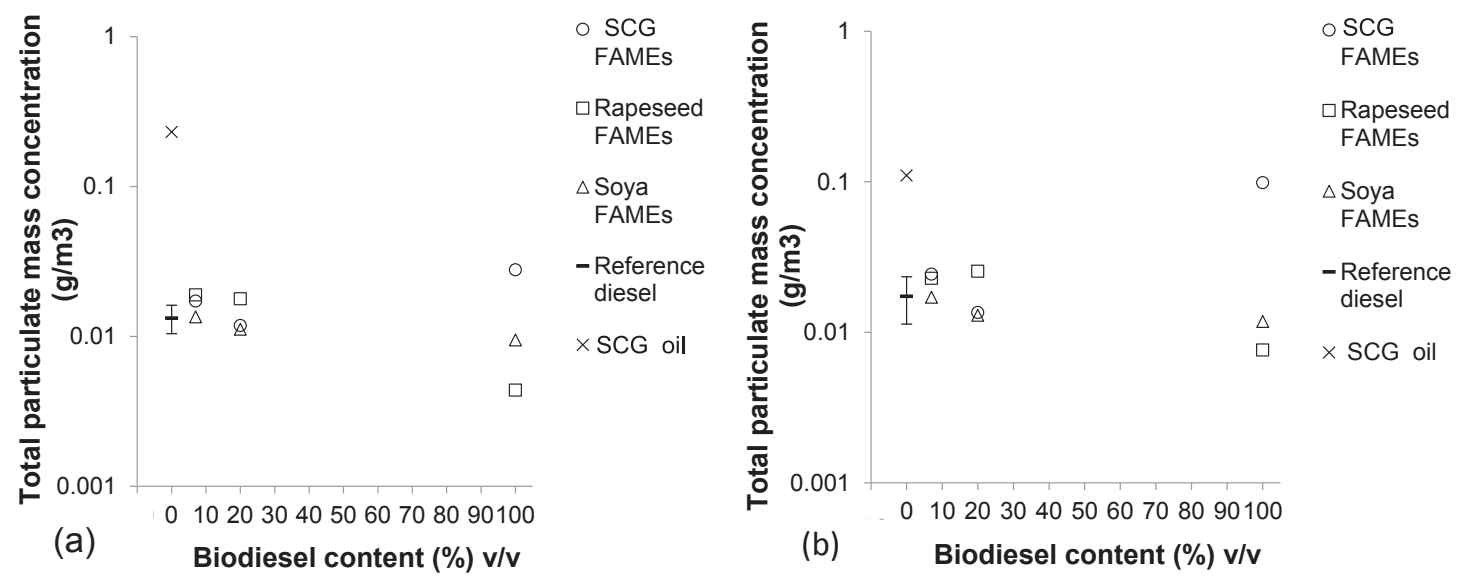

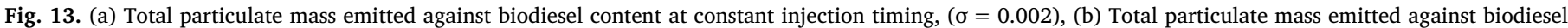
content at constant ignition timing, $(\sigma=0.006)$.

cannot justify the hundred times higher number of particulates produced by the neat SCG biodiesel.

It is therefore tentatively suggested that the presence of C18:3n6 methyl esters in SCG biodiesel, which were not found in either of soya or rapeseed biodiesels (Table 2), may have contributed to the elevated particulates emissions from the SCG biodiesel. The C18:3n6 methyl esters contain double bonds positioned centrally along the fatty acid alkyl chain (i.e. the chemical name is all-cis-6,9,12-octadecatrienoic acid), therefore reducing the length of saturated alkyl chains present within the fatty acid moiety relative to C18:3n3 methyl esters, found in all three biodiesel varieties (Table 2). This hypothesis is supported by previous studies that investigated the sooting tendencies of a range of esters [11] and decene isomers [29], with a single double bond in open flames, and reported that the central position of a double bond increased sooting tendancy. This was suggested to be through the favoured production of aromatic rings (essential precursors for the production of soot via the formation of polycyclic aromatics) where the position of the double bond reduced the length of saturated alkyl chains $[11,29]$.

A further speculative suggestion is that that the SCG biodiesel contained other unidentified compounds which are not typically found in more commonly utilised vegetable oils for biodiesel production resulted in an increase of the number of particles emitted upon combustion, however, further analysis of the SCG biodiesel would be necessary to substantiate this. Finally, Fig. 12 shows that the combustion of blended samples with $20 \%$ and $7 \% \mathrm{v} / \mathrm{v}$ biodiesel content emitted lower amounts of particulates relative to neat biodiesel samples at both experimental conditions, something attributed to the lower quantity of biodiesel in the samples, while small variations can be observed between samples.

Fig. 13(a) and (b) show the total particulate mass emitted by the various fuel samples and reference fossil diesel at constant injection and constant ignition timing respectively.

Fig. 13(a) shows that the use of raw SCG oil as an engine fuel resulted in particulate mass emissions significantly higher than those observed when the neat and blended biodiesel samples were tested at conditions of constant injection timing, in agreement with the higher number of particles emitted (Fig. 12(a)). Fig. 13(b) shows that raw SCG oil produced a much lower concentration of particulates at conditions of constant ignition timing, about half of that produced at constant injection, while the total mass of particulates produced by neat SCG biodiesel was similar to that of the raw SCG oil, an observation coinciding with the particle number distribution of the two fuels at this condition (Fig. 12(d)).

\section{Conclusions}

1. Acid-catalyzed pretreatement of SCG oil successfully reduced the FFA content below $1.5 \% \mathrm{w} / \mathrm{w}$ with minor losses $(1.31 \pm 0.73 \% \mathrm{w} /$ $\mathrm{w}$ of the initial untreated oil weight) and the subsequent base-catalyzed transesterification achieved a maximum FAME conversion yield of $87.83 \pm 0.47 \% \mathrm{w} / \mathrm{w}$ relative to pretreated oil weight.

2. Within the range of investigated conditions, the efficiency of acidcatalyzed pretreatment was found to be more closely related to the methanol-to-FFA molar ratio and less to the sulfuric acid weight percentage relative to FFAs, while in the subsequent base-catalyzed process the catalyst-to-oil weight percentage had a more profound effect.

3. Combustion of raw SCG oil resulted in the lowest in-cylinder peak pressure and PHRR relative to the other fuels samples despite a long ignition delay, indicating inadequate mixing and incomplete burning, possibly due to poor atomization resulting from high $\mathrm{KV}$, and suggesting the oil physical properties to be more important in determining the fuel premixed fraction than the duration of ignition delay. These observations were supported by the low $\mathrm{NO}_{\mathrm{x}}$ and high THC, CO and particulate emissions of raw SCG oil.

4. Combustion and emission characteristics of pure and blended SCG biodiesel showed similarities with other vegetable biodiesel samples tested, suggesting SCG oil to be a suitable feedstock for production of biodiesel. The higher CO, THC and particulate emissions of the SCG FAMEs relative to soya and rapeseed biodiesel can be attributed to a relatively high $\mathrm{KV}$ that inhibited air-fuel mixing and resulted in increased presence of fuel rich zones suitable for particulates formation within the cylinder.

5. The ignition delay of biodiesel blends was found to correlate well with the biodiesel content of the sample, with an increase of biodiesel content from $7 \% \mathrm{v} / \mathrm{v}$ to $100 \% \mathrm{v} / \mathrm{v}$ resulting in decrease of the ignition delay time.

\section{Acknowledgements}

The authors would like to thank bio-bean Ltd. for providing financial support throughout this study. Funds for this research were also provided by EPSRC Grant EP/M007960/1.

\section{Appendix A. Supplementary data}

Supplementary data to this article can be found online at https:// doi.org/10.1016/j.fuel.2019.03.040. 


\section{References}

[1] Al-Hamamre Z, Foerster S, Hartmann F, Kröger M, Kaltschmitt M. Oil extracted from spent coffee grounds as a renewable source for fatty acid methyl ester manufacturing. Fuel 2012;96:70-6. https://doi.org/10.1016/j.fuel.2012.01.023.

[2] Berhe MH, Asfaw A, Asfaw N. Investigation of waste coffee ground as a potential raw material for biodiesel production. Int J Renew Energy Res 2013;3:854-60.

[3] BP. 2017. BP Statistical Review of World Energy 2017. Br. Pet. 1-52. https://doi org/http://www.bp.com/content/dam/bp/en/corporate/pdf/energy-economics/ statistical-review-2017/bp-statistical-review-of-world-energy-2017-full-report.pdf.

[4] BSI Standard, 2014. BS EN 14214:2012+A1; 2014.

[5] Caetano NS, Silva VFM, Melo AC, Martins AA, Mata TM. Spent coffee grounds for biodiesel production and other applications. Clean Technol Environ Policy 2014;16:1423-30. https://doi.org/10.1007/s10098-014-0773-0.

[6] Caetano NS, Silvaa VFM, Mata TM. Valorization of coffee grounds for biodiesel production. Chem Eng Trans 2012:267-72. https://doi.org/10.3303/CET1226045.

[7] Calixto F, Fernandes J, Couto R, Hernández EJ, Najdanovic-Visak V, Simões PC. Synthesis of fatty acid methyl esters via direct transesterification with methanol/ carbon dioxide mixtures from spent coffee grounds feedstock. Green Chem 2011;13:1196. https://doi.org/10.1039/c1gc15101k.

[8] Canakci M, Gerpen J Van. Biodiesel production from oils and fats with high free fatty acids. Trans ASAE 2001;44:1429-36. https://doi.org/10.1016/j.fuel.2013.09. 020.

[9] Canakci M, Sanli H. Biodiesel production from various feedstocks and their effects on the fuel properties. J Ind Microbiol Biotechnol 2008. https://doi.org/10.1007/ s10295-008-0337-6.

[10] Chai M, Tu Q, Lu M, Yang YJ. Esterification pretreatment of free fatty acid in biodiesel production, from laboratory to industry. Fuel Process Technol 2014;125:106-13. https://doi.org/10.1016/j.fuproc.2014.03.025.

[11] Das DD, McEnally CS, Pfefferle LD. Sooting tendencies of unsaturated esters in nonpremixed flames. Combust Flame 2015;162:1489-97. https://doi.org/10.1016/ j.combustflame.2014.11.012.

[12] Deligiannis A, Papazafeiropoulou A, Anastopoulos G, Zannikos F. 2011. Waste coffee grounds as an energy feedstock. In: Proceeding 3rd Int. CEMEPE SECOTOX Conf. p. 617-22.

[13] Demirbas A. Competitive liquid biofuels from biomass. Appl Energy 2011. https:// doi.org/10.1016/j.apenergy.2010.07.016.

[14] Eevera T, Rajendran K, Saradha S. Biodiesel production process optimization and characterization to assess the suitability of the product for varied environmental conditions. Renew Energy 2009;34:762-5. https://doi.org/10.1016/j.renene.2008. 04.006.

[15] Efthymiopoulos I, Hellier P, Ladommatos N, Kay A, Mills-Lamptey B. Integrated strategies for water removal and lipid extraction from coffee industry residues. Sustain Energy Technol Assessments 2018;29:26-35. https://doi.org/10.1016/J. SETA.2018.06.016.

[16] Efthymiopoulos I, Hellier P, Ladommatos N, Kay A, Mills-Lamptey B. Effect of solvent extraction parameters on the recovery of oil from spent coffee grounds for biofuel production. Waste Biomass Valorization 2017. https://doi.org/10.1007/ s12649-017-0061-4.

[17] Efthymiopoulos I, Hellier P, Ladommatos N, Russo-Profili A, Eveleigh A, Aliev A, et al. Influence of solvent selection and extraction temperature on yield and composition of lipids extracted from spent coffee grounds. Ind Crops Prod 2018;119. https://doi.org/10.1016/j.indcrop.2018.04.008.

[18] Ferrario V, Veny H, De Angelis E, Navarini L, Ebert C, Gardossi L. Lipases immobilization for effective synthesis of biodiesel starting from coffee waste oils. Biomolecules 2013;3:514-34. https://doi.org/10.3390/biom3030514.

[19] Haile M. Integrated volarization of spent coffee grounds to biofuels. Biofuel Res J 2014;2:65-9. https://doi.org/10.18331/BRJ2015.1.2.6.

[20] Hellier P, Ladommatos N. The influence of biodiesel composition on compression ignition combustion and emissions. Proc Inst Mech Eng Part A J Power Energy 2015;229:714-26. https://doi.org/10.1177/0957650915598424.

[21] Hellier P, Ladommatos N, Allan R, Payne M, Rogerson J. The impact of saturated and unsaturated fuel molecules on diesel combustion and exhaust emissions. SAE Int J Fuels Lubr 2011;5:106-22. https://doi.org/10.4271/2011-01-1922.

[22] Hellier P, Ladommatos N, Allan R, Rogerson J. Combustion and emissions characteristics of toluene/n-heptane and 1-octene/n-octane binary mixtures in a direct injection compression ignition engine. Combust Flame 2013;160:2141-58. https:// doi.org/10.1016/j.combustflame.2013.04.016.

[23] Hellier P, Ladommatos N, Allan R, Rogerson J. The influence of fatty acid ester alcohol moiety molecular structure on diesel combustion and emissions. Energy Fuels 2012;26:1912-27. https://doi.org/10.1021/ef2017545.

[24] Hellier P, Ladommatos N, Yusaf T. The influence of straight vegetable oil fatty acid composition on compression ignition combustion and emissions. Fuel 2015;143:131-43. https://doi.org/10.1016/j.fuel.2014.11.021.

[25] IEA. CO2 emissions from fuel combustion-highlights. IEA Stat; 2017.

[26] IKA Calorimeter C1, Operating instructions [WWW Document], n.d. accessed on (31/3/2017). URL http://www.ika.com/owa/ika/catalog.product downloads? iProduct $=3825000 \&$ iProductgroup $=\&$ iSubgroup $=\& \mathrm{iCS}=1 \& \mathrm{iAcc}=\& \mathrm{iCon}=$.

[27] Jenkins RW, Stageman NE, Fortune CM, Chuck CJ. Effect of the type of bean, processing, and geographical location on the biodiesel produced from waste coffee grounds. Energy Fuels 2014;28:1166-74. https://doi.org/10.1021/ef4022976.

[28] Kardash E, Tur YI. Acid value determination in vegetable oils by indirect titration in aqueous-alcohol media. Croat Chem Acta 2005;78:99-103.

[29] Kholghy MR, Weingarten J, Sediako AD, Barba J, Lapuerta M, Thomson MJ. Structural effects of biodiesel on soot formation in a laminar coflow diffusion flame.
Proc Combust Inst 2017;36:1321-8. https://doi.org/10.1016/j.proci.2016.06.119.

[30] Knothe G. "Designer" biodiesel: optimizing fatty ester composition to improve fuel properties. Energy Fuels 2008;22:1358-64. https://doi.org/10.1021/ef700639e.

[31] Knothe G. Dependence of biodiesel fuel properties on the structure of fatty acid alkyl esters. Fuel Process Technol 2005;86:1059-70. https://doi.org/10.1016/j. fuproc.2004.11.002.

[32] Knothe G, Steidley KR. Kinematic viscosity of biodiesel fuel components and related compounds. Influence of compound structure and comparison to petrodiesel fuel components. Fuel 2005. https://doi.org/10.1016/j.fuel.2005.01.016.

[33] Koivisto EK. 2016. Ignition and combustion of future oxygenated fuels in compression-ignition engines. Doctoral thesis, UCL (University College of London).

[34] Koivisto E, Ladommatos N, Gold M. Compression ignition and pollutant emissions of large alkylbenzenes. Fuel 2016;172:200-8. https://doi.org/10.1016/j.fuel.2016. 01.025 .

[35] Koivisto E, Ladommatos N, Gold M. Systematic study of the effect of the hydroxyl functional group in alcohol molecules on compression ignition and exhaust gas emissions. Fuel 2015;153:650-63. https://doi.org/10.1016/j.fuel.2015.03.042.

[36] Koivisto E, Ladommatos N, Gold M. The influence of various oxygenated functional groups in carbonyl and ether compounds on compression ignition and exhaust gas emissions. Fuel 2015;159:697-711. https://doi.org/10.1016/j.fuel.2015.07.018.

[37] Kombe GG, Temu AK, Rajabu HM, Mrema GD. 2012. High free fatty acid (FFA) feedstock pre-treatment method for biodiesel production. In: Second Int. Conf. Adv. Eng. Technol. p. 176-82.

[38] Kondamudi N, Mohapatra SK, Misra M. Spent coffee grounds as a versatile source of green energy. J Agric Food Chem 2008;56:11757-60. https://doi.org/10.1021/ jf802487s.

[39] Kwon EE, Yi H, Jeon YJ. Sequential co-production of biodiesel and bioethanol with spent coffee grounds. Bioresour Technol 2013;136:475-80. https://doi.org/10. 1016/j.biortech.2013.03.052.

[40] Leung DYC, Wu X, Leung MKH. A review on biodiesel production using catalyzed transesterification. Appl Energy 2010. https://doi.org/10.1016/j.apenergy.2009. 10.006.

[41] Liu Y, Tu Q, Knothe G, Lu M. Direct transesterification of spent coffee grounds for biodiesel production. Fuel 2017;199:157-61. https://doi.org/10.1016/j.fuel.2017. 02.094.

[42] Meher LC, Dharmagadda VSS, Naik SN. Optimization of alkali-catalyzed transesterification of Pongamia pinnata oil for production of biodiesel. Bioresour Technol 2006;97:1392-7. https://doi.org/10.1016/j.biortech.2005.07.003.

[43] Monyem A, Van Gerpen HJ. The effect of biodiesel oxidation on engine performance and emissions. Biomass Bioenergy 2001. https://doi.org/10.1016/S0961 9534(00)00095-7.

[44] Mueller CJ, Boehman AL, Martin GC. An experimental investigation of the origin of increased $\mathrm{NO}_{\mathrm{x}}$ emissions when fueling a heavy-duty compression-ignition engine with soy biodiesel. SAE Int J Fuels Lubr 2009;2. https://doi.org/10.4271/2009-011792. 2009-01-1792.

[45] Najdanovic-Visak V, Lee FYL, Tavares MT, Armstrong A. Kinetics of extraction and in situ transesterification of oils from spent coffee grounds. J Environ Chem Eng 2017;5:2611-6. https://doi.org/10.1016/j.jece.2017.04.041.

[46] Park J, Kim B, Lee JW. In-situ transesterification of wet spent coffee grounds for sustainable biodiesel production. Bioresour Technol 2016;221:55-60. https://doi. org /10.1016/j.biortech.2016.09.001.

[47] Park K, Kittelson DB, Zachariah MR, McMurry PH. Measurement of inherent material density of nanoparticle agglomerates. J Nanoparticle Res 2004;6:267-72. https://doi.org/10.1023/B:NANO.0000034657.71309.e6.

[48] Pinzi S, Garcia IL, Lopez-Gimenez FJ, DeCastro MDL, Dorado G, Dorado MP. The ideal vegetable oil-based biodiesel composition: a review of social, economical and technical implications. Energy Fuels 2009;23:2325-41. https://doi.org/10.1021/ ef801098a.

[49] REN21. Renewables 2017: global status report. Renew Sustain Energy Rev 2017. https://doi.org/10.1016/j.rser.2016.09.082.

[50] Rocha MVP, de Matos LJBL, de Lima LP, Figueiredo PM da S, Lucena IL, Fernandes FAN, Gonçalves LRB. Ultrasound-assisted production of biodiesel and ethanol from spent coffee grounds. Bioresour Technol 2014;167:343-8. https://doi.org/10. 1016/j.biortech.2014.06.032.

[51] Sadrameli SM, Seames W, Mann M. Prediction of higher heating values for saturated fatty acids from their physical properties. Fuel 2008;87:1776-80. https://doi org/10.1016/j.fuel.2007.10.020.

[52] Schönborn A, Ladommatos N, Williams J, Allan R. 2007. Effects on diesel combustion of the molecular structure of potential synthetic bio-fuel molecules effects on diesel combustion of the molecular structure of potential synthetic bio-fuel molecules. SAE Tech Pap 24.

[53] Schönborn A, Ladommatos N, Williams J, Allan R, Rogerson J. The influence of molecular structure of fatty acid monoalkyl esters on diesel combustion. Combust Flame 2009;156:1396-412. https://doi.org/10.1016/j.combustflame.2009.03.011.

[54] Sergeeva YE, Mostova EB, Gorin KV, Komova AV, Konova IA, Pojidaev VM, Gotovtsev PM, Vasilov RG, Sineoky SP. Calculation of biodiesel fuel characteristics based on the fatty acid composition of the lipids of some biotechnologically important microorganisms. Appl. Biochem. Microbiol 2017. https://doi.org/10.1134/ S0003683817080063.

[55] Song H, Quinton K, Peng Z, Zhao H, Ladommatos N. Effects of oxygen content of fuels on combustion and emissions of diesel engines. Energies 2016;9:28. https:// doi.org/10.3390/en9010028.

[56] Swanepoel W, Karmee SK, Marx S. 2016. Biocatalytic production of biodiesel from spent coffee grounds. In: International Conference on Advances in Science, Engineering, Technology and Natural Resources (ICASETNR-16). Parys (South Africa). 
[57] Szybist JP, Boehman AL, Taylor JD, McCormick RL. Evaluation of formulation strategies to eliminate the biodiesel NOx effect. Fuel Process Technol 2005;86:1109-26. https://doi.org/10.1016/j.fuproc.2004.11.006.

[58] Tuntiwiwattanapun N, Monono E, Wiesenborn D, Tongcumpou C. In-situ transesterification process for biodiesel production using spent coffee grounds from the instant coffee industry. Ind Crops Prod 2017;102:23-31. https://doi.org/10.1016/j. indcrop.2017.03.019.

[59] Vardon DR, Moser BR, Zheng W, Witkin K, Evangelista RL, Strathmann TJ, et al. Complete utilization of spent coffee grounds to produce biodiesel, bio-oil, and biochar. ACS Sustain Chem Eng 2013;1:1286-94. https://doi.org/10.1021/ sc400145w.

[60] Vyas AP, Verma JL, Subrahmanyam N. Effects of molar ratio, alkali catalyst concentration and temperature on transesterification of jatropha oil with methanol under ultrasonic irradiation. Adv Chem Eng Sci 2011;01:45-50. https://doi.org/10 4236/aces.2011.12008.

[61] Yanowitz J, Ratcliff MA, McCormick RL, Taylor JD, Murphy MJ. 2017. Compendium of experimental cetane number. https://doi.org/10.2172/1345058. 